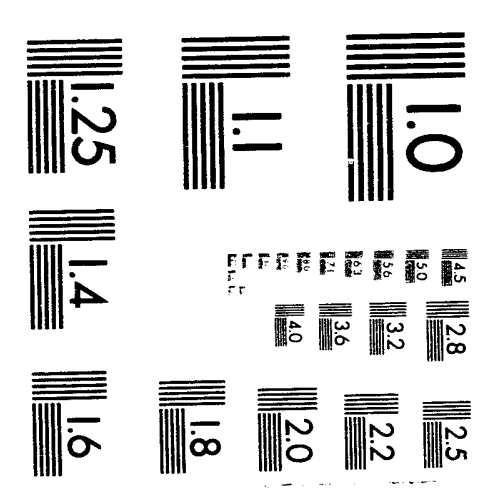



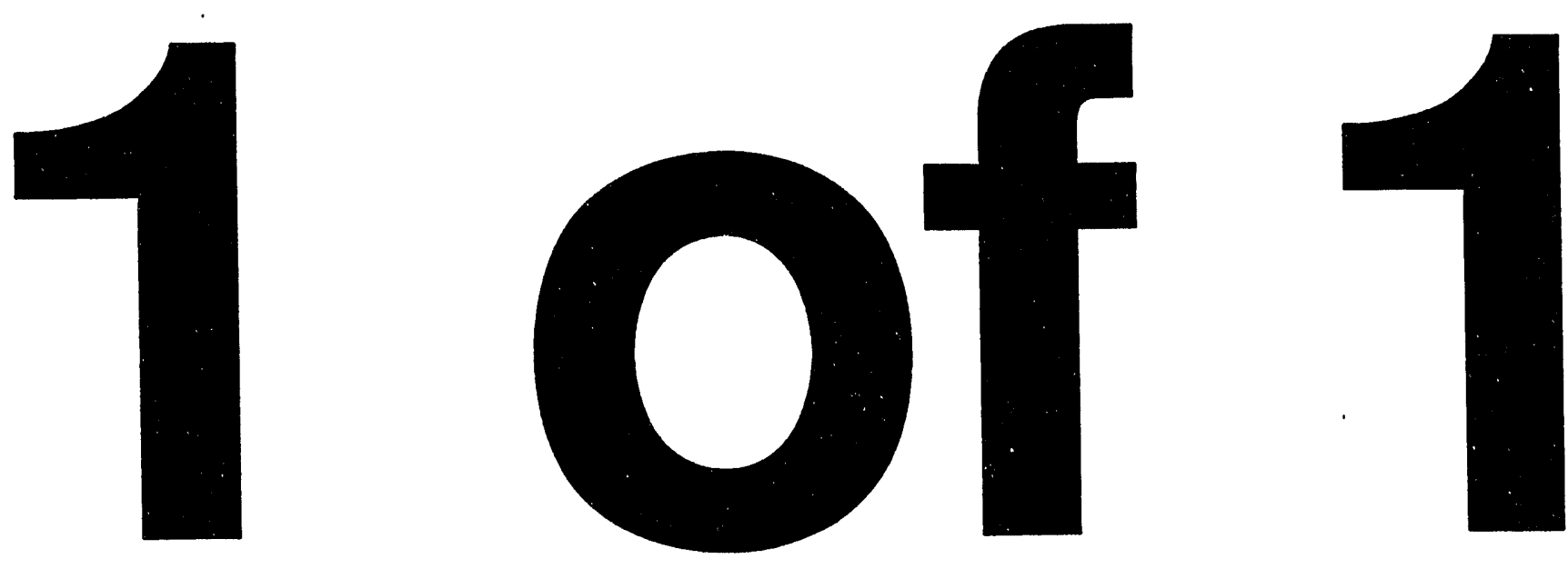


\section{The Theory and Practice of Decoupling}

Joseph Eto, Steven Stoft, and Timothy Belden

Energy \& Environment Division

Lawrence Berkeley Laboratory

University of California

Berkeley, CA 94720

January 1994

The work described in this report was funded by the Assistant Secretary for Conservation and Renewable Energy, Office of Utility Technologies, Office of Energy Management of the U.S. Department of Energy under Contract No. DE-AC03-76SF00098. 


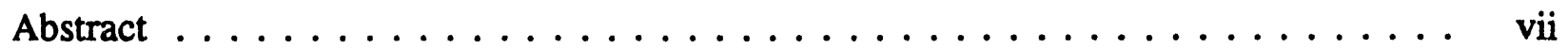

Acknowledgements $\ldots \ldots \ldots \ldots \ldots \ldots \ldots \ldots \ldots \ldots \ldots \ldots \ldots \ldots \ldots$

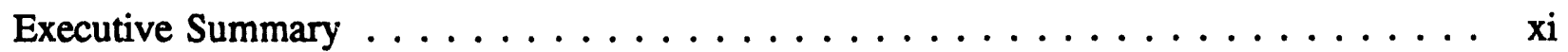

Chapter 1

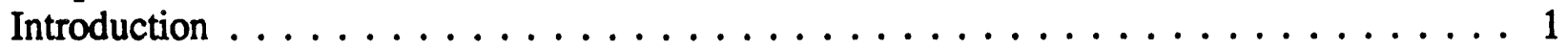

Chapter 2

How Does Traditional Ratemaking Influence the Profitability of Incremental Sales? . . . 5

The Between-Rate-Case Incentive to Sell Electricity . . . . . . . . . . . . . . 5

The Rate Case is a Limit to this Incentive . . . . . . . . . . . . . . . . . . . . . . . . . . . . . .

The Other Incentive to Sell Electricity . . . . . . . . . . . . . . 13

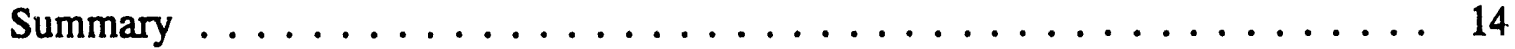

Chapter 3

Decoupling Revenue Adjustment Mechanisms . . . . . . . . . . . . . . 15

Ratemaking Fundamentals ... . . . . . . . . . . . . . . . 15

Decoupling Revenue Adjustment Mechanisms . . . . . . . . . . . . . . 18

A Look at Specific Decoupling RAMs ... . . . . . . . . . . . . . 21

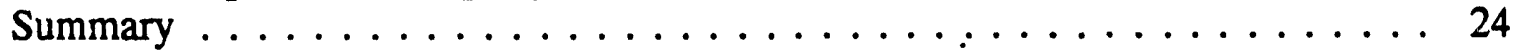

Chapter 4

Sales Versus Customers as Determinants of Nonfuel Costs . . . . . . . . . . . . . 25

Aggregate Utility Data on Sales, Customers, and Costs . . . . . . . . . . . 25

Regression Analysis of Selected Determinants of Nonfuel Costs . . . . . . . . . 29

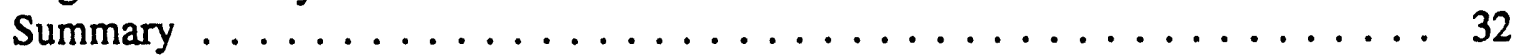

Chapter 5

Evaluation of Decovpling Revenue Adjustment Mechanisms . . . . . . . . . . . 33

Four Decoupling Revenue Adjustment Mechanisms . . . . . . . . . . . 33

Evaluation of RAM Performance $\ldots \ldots \ldots \ldots \ldots \ldots \ldots \ldots$

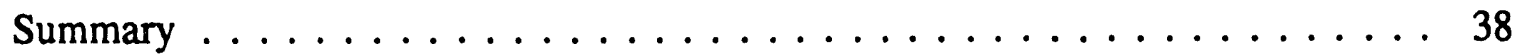


Chapter 6

The Historic Rate Impacts of ERAM in California $\ldots \ldots \ldots \ldots \ldots \ldots \ldots$

Tracing the History of ERAM in California . . . . . . . . . . . 41

California Electricity Rate History . . . . . . . . . . . . . . . . . 42

Electricity Rate Changes With and Without ERAM ... . . . . . . 44

Has ERAM Shifted Rate Risk? . . . . . . . . . . . . . . . . 46

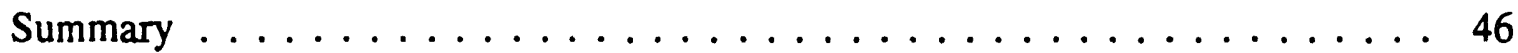

Chapter 7

Conclusions . . . . . . . . . . . . . . . . . . . . . . . . 49

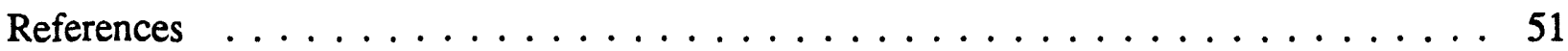

Appendix A

Calculating the Profitability of Incremental Sales $\ldots \ldots \ldots \ldots \ldots$

Appendix B

Discussion of FERC Form-1 Data $\ldots \ldots \ldots \ldots \ldots \ldots$. . . . . . . 57

Selecting a Data Source $\ldots \ldots \ldots \ldots \ldots \ldots \ldots \ldots \ldots$

Screening the Data $\ldots \ldots \ldots \ldots \ldots \ldots \ldots \ldots \ldots \ldots$

Appendix C

Discussion of Statistical Analysis . . . . . . . . . . . . . . . 61

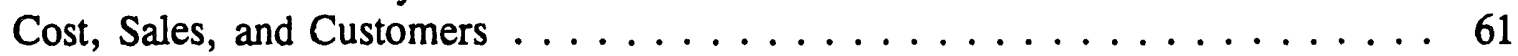

Additional Variables . . . . . . . . . . . . . . . 62

Lagged Variables . . . . . . . . . . . . . . . . . . . 63

Expected and Unexpected Changes $\ldots \ldots \ldots \ldots \ldots \ldots \ldots 6$

Summary . . . . . . . . . . . . . . . . . . 65

Appendix D

Calculating the Cost of Risk . . . . . . . . . . . . . . . . . . 67

Is Rate Risk Correlated with Consumer Income? . . . . . . . . . . . . . 67 
Table EX-1. Annual Changes in Revenue Requirement and Retail Rates . . . xvii

Table 2-1. Profitability of $1 \%$ Sales Increase Without Decoupling-Examples . . 6

Table 2-2. Cost Structure of U.S. Investor-Owned Electric Utilities . . . . . . 10

Table 3-1. Basic RAM Example ... . . . . . . . . . . . . . . . . . . . 19

Table 3-2. Comparison of Ratemaking Approaches . . . . . . . . . . . . 24

Table 5-1. Comparison of Revenue-Setting Approaches . . . . . . . . . . 34

Table 6-1. Annual Percent Changes in Revenue Requirement and Retail Rates ... . . . . . . . . . . . . . . . . . . . 44

Table B-1. Utilities and Reporting Years Used in LBL Analysis . . . . . . . 60

Table C-1. "Stepwise" Regression Results . . . . . . . . . . . . . . 62

Table C-2. Lagged Variable Regression Results . . . . . . . . . . . . . . 63

Table C-3. Expected and Unexpected Sales Change Regressions . . . . . . . 64

Table D-1. Calculation of Risk-Shifting Premiums . . . . . . . . . . . . . 69 
Figure EX-1. Profitability of $1 \%$ Sales Increase . . . . . . . . . . . . xiii

Figure EX-2. Profitability of Traditional Ratemaking and Decoupling Revenue Adjustment Mechanisms ................. xv

Figure $2-1 . \quad$ Profitability of $1 \%$ Sales Increase ................ . 9

Figure 2-2. The Rate Case as a Limit to the Profitability of Sales Increases . . 12

Figure 4-1. Uses of Revenue for Major Investor-Owned Electric Utilities . . . 28

Figure 5-1. Profitability of Traditional Ratemaking and Decoupling Revenue Adjustment Mechanisms .................. 35

Figure 6-1. Changes in Authorized Revenue Requirement and Average Retail Rates ... . . . . . . . . . . . . . . . . . . 43

Figure 6-2. Changes in Average Retail Rates With and Without ERAM ... 45

Figure A-1. Break-Even Profitability for a $1 \%$ Increase in Sales . . . . . . . . 56 
$-2$ 
Decoupling revenues from sales is an important regulatory option under consideration by regulators seeking to transform utilities from sellers of a least-cost energy commodity to providers of least-cost energy services. This report examines decoupling from three perspectives. First, we consider threshold issues for decoupling, including characterization of the ratemaking practices addressed by decoupling which make incremental sales profitable to utilities, the role of rate case frequency in limiting the consequences of this incentive, and finally the existence of other incentives to sell electricity, which are not addressed by decoupling. Second, we examine the operation and performance of decoupling, including the mechanics of decoupling as a between-ratecase modification to the traditional ratemaking process, the ability of revenue-percustomer decoupling versus traditional ratemaking to recover nonfuel costs accurately, and a comparison of the profit implications of various decoupling approaches. Third, we review the rate impacts of decoupling for California's electric utilities, which have had the longest experience with decoupling. 
This report has benefitted from the reviews and comments from a number of individuals, including Ron Binz, CO OCC; Terry Black, PACE; Ralph Cavanagh, NRDC; Tom Foley, PNL; Paul Galen, NREL; Bob Griniere, NRRI; Mark Hellman, OR PUC; Eric Hirst, ORNL; David Moskovitz, RAP; John Stutz, Tellus; and Rick Weston, VT PSB. In addition, we are grateful for the efforts of the following utility and public utility commission staff in providing information used in the report: John Clarke, Bruce Smith, and Gary Irwin, PG\&E; Akbar Jazayeri and Randy Lisbin, SCE; Jim Frank, SDG\&E; L. Mario DiValentino, Orange \& Rockland; Scarlett Liang-Uejio, CPUC; Bill Mills, NY PSC; and Ken Elgin, WA UTC. Finally, the authors would also like to acknowledge the help and support of their LBL colleagues including G. Alan Comnes, Chuck Goldman, Ed Kahn, and especially, Ellen Hodges.

The work described in this report was funded by the Assistant Secretary for Conservation and Renewable Energy, Office of Utility Technologies, Office of Energy Management of the U.S. Department of Energy under Contract No. DE-AC03-76SF00098. 
Alfred Kahn once said "all regulation is incentive regulation." Nowhere is the challenge that is implicit in this observation greater than in current debates about regulatory reforms in support of integrated resource planning. Integrated resource planning (IRP) requires that a utility consider all resource options for meeting customers' energy service needs in a consistent fashion. For both demand-side and nontraditional resources, questions have been raised about the appropriateness of traditional utility rate regulation for aligning utilities' earnings incentives with the goals of IRP. If the utility management cannot increase shareholder earnings through better procurement of resources, why should we expect that they will be efficient?

Specific disincentives that have been noted for customer energy efficiency programs include: (1) utilities may not recover demand-side management (DSM) program expenses when these expenses have not been accounted for in some previous rate-setting process; (2) utilities may lose revenue from sales not made because of the success of customer energy efficiency programs; and (3) utilities may forego earnings opportunities because resources are devoted to DSM programs rathei usan to other profit-making activities.

Various regulatory changes have been proposed to address these disincentives. Of these, decoupling, which addresses the issue of lost revenues, has been the subject of controversy. Decoupling refers to a class of automatic or semi-automatic annual ratemaking adjustments that ensure collection of an agreed-upon level of revenues independent of actual sales.

Proponents argue that, without decoupling, a utility has powerful incentives to promote incremental sales and equally powerful disincentives to reduce sales growth through successful DSM programs. According to this perspective, decoupling is required in order to make utilities indifferent to sales gains or losses ${ }^{1}$ and thereby to free utilities to promote customer energy efficiency programs, in order to achieve integrated resource planning objectives.

Opponents raise concerns about several aspects of decoupling. First, they question the exact nature and size of the incentive for incremental sales and the ability of decoupling to mitigate this incentive. Second, decoupling represents a form of automatic

\footnotetext{
' For this reason, proponents of decoupling also argue that decoupling is superior to net lost revenue adjustments because these adjustments deal only with revenue losses directly attributable to utility DSM activities while leaving the underlying incentive to make incremental sales unaffected.
} 
ratemaking, so it could diminish the centrality of the rate case as the primary forum for examining (and contesting) utility practices. Third, decoupling, as implemented currently, may inappropriately shift business risks from utility shareholders to ratepayers, possibly leading to undesirable rate impacts.

The goal of this report is to provide a broad framework in which to address these concerns. We have structured our work around three questions: (1) Why decouple? (2) How does decoupling work? (3) What have been the rate impacts of decoupling?

\section{Why Decouple?}

Stated simply, there is an incentive for a utility to sell additional electricity whenever marginal revenues exceed marginal costs. Between rate cases, because prices are fixed by definition (i.e., to a first approximation, marginal revenue equals average revenue), profitability is determined by the cost structure of the utility. We demonstrate analytically how, between rate cases, profits depend on: (1) the initial profit margin of the utility (prior to the incremental sales); (2) the fraction of total costs affected by the production expenses incurred to make incremental sales (i.e., the variable cost fraction); and (3) the way in which this fraction is affected (i.e., marginal versus average variable costs).

The analysis provides a generalizable approach for assessing specific claims of profitability (e.g., "a $1 \%$ increase in sales leads to $X$ additional basis points in return on equity"). Using this approach, we find that the cost structures of most investor-owned utilities do indeed make incremental sales profitable. See Figure EX-1.

At the same time, the frequency of rate cases limits the opportunities for these marginal revenue/marginal cost relationships to make incremental sales profitable. In this regard, the incentive to sell electricity between rate cases is simply a consequence of regulatory lag.

Finally, we believe there are there other incentives, besides regulatory lag, for utilities to build load. The issue for decoupling is whether there truly are incentives (or really disincentives) and, if there are incentives, how are they addressed by decoupling? We believe a broader discussion of these issues is appropriate when considering decoupling as a remedy for the lost revenue problem. 
Figure EX-1. Profitability of $1 \%$ Sales Increase

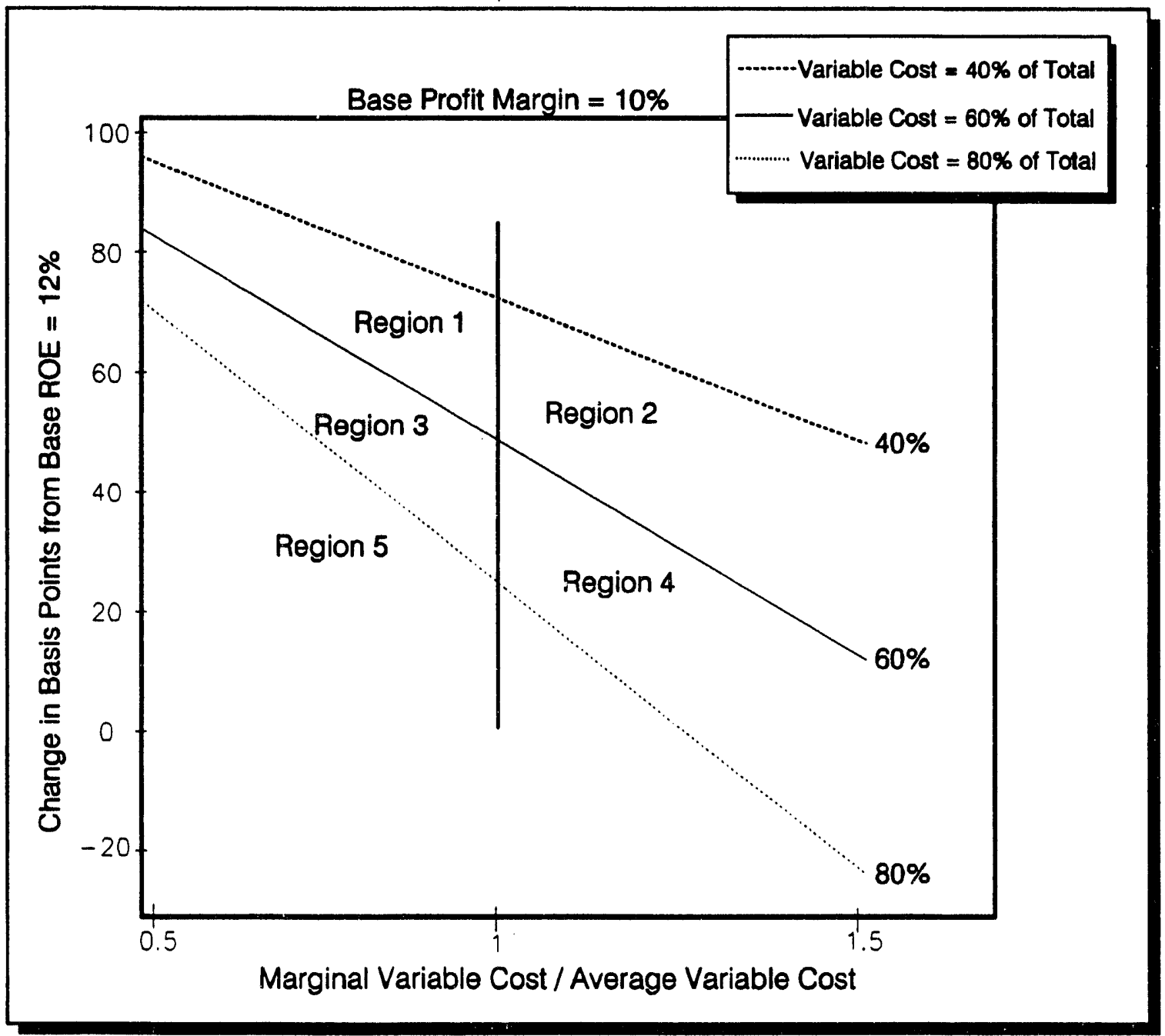

Figure EX-1 illustrates the relationship between a $1 \%$ increase in sales and the resulting increase (or decrease) in profit. The results are presented for three levels of variable costs as a fraction of total costs $(40 \%, 60 \%$ and $80 \%)$, which are represented by three downward-sloping horizontal lines. Alternative marginal variable to average variable cost relationships are represented along the horizontal axis. The resulting change in profit, expressed as a change in return on equity, normalized to an in al $12 \%$, is depicted on the vertical axis. Using FERC Form-1 data from 1987 and 1988, we mapped the current cost structure of U.S. electric utilities onto this graph. Of the 122 utilities examined, 33\% are in Region 1, 20\% are in Region 2, 31\% are in Region 3, 12\% are in Region 4, and $4 \%$ are in Region 5. This graph indicates that, when prices are fixed, there are very few situations in which increased sales cannot lead to increased profits. 


\section{How Does Decoupling Work?}

Looking at the specific operation of decoupling mechanisms, we observe that the critical distinction between traditional ratemaking and decoupling lies with the focus and frequency of the ratemaking process. Traditional ratemaking focusses on rate-setting in the context of a rate case cycle, which typically spans many years. Decoupling does not change this basic process, but adds to it an explicit means for setting revenues during the period between rate cases. In so doing, decoupling eliminates the incentive to increase sales between rate cases, since revenues will be unaffected by actual sales.

We develop formal expressions that describe the rate-setting mechanics of traditional ratemaking and all current forms of decoupling: the Electric Revenue Adjustment Mechanism (ERAM), as practiced in California; the related Revenue Decoupling Mechanism (RDM) used in New York; and the Revenue-Per-Customer approach (RPC), as practiced by Central Maine Power in Maine and Puget Power in Washington.

We evaluate the ratemaking approaches by first examining how traditional ratemaking and RPC treat cost-recovery between rate cases. This perspective is important because setting rates equal to the cost of service is a fundamental principle of the ratemaking process. The inability of rates to recover costs is a primary justification of holding rate cases tc realign rates and costs. Because most utilities operate with some form of fuel adjustment clause, which passes fuel and purchased power costs through to consumers, the generic issue is how each ratemaking process accounts for nonfuel cost changes. Traditional ratemaking, by fixing prices between rate cases, links the recovery of nonfuel costs to changes in load. RPC, by recoupling revenues to numbers of customers links the recovery of these costs to changes in the number of customers. ${ }^{2}$

Relying on 25 years of aggregate financial statistics from 160 investor-owned utilities, we find that one-year changes in load or numbers of customers are both poorly-correlated with changes in nonfuel costs. Hence, the proponents of RPC are correct in arguing that RPC does no worse than traditional ratemaking in tracking nonfuel costs (indeed, we find it does slightly better). Nevertheless, as long as cost of service is an important ratemaking principle, there will remain a need for periodic rate cases under both traditional ratemaking and RPC decoupling.

Using the same historic data, we then directly examine the profitability bias inherent in each ratemaking approach; the results are summarized in Figure EX-2. We find, as was

\footnotetext{
2 The assumptions regarding nonfuel cost changes cannot be readily examined for ERAMs because ERAMs recouple sales to attrition mechanisms, which vary greatly in the way in which they adjust authorized revenue requirements between rate cases.
} 
Figure EX-2. Profitability of Traditional Ratemaking and Decoupling Revenue Adjustment Mechanisms

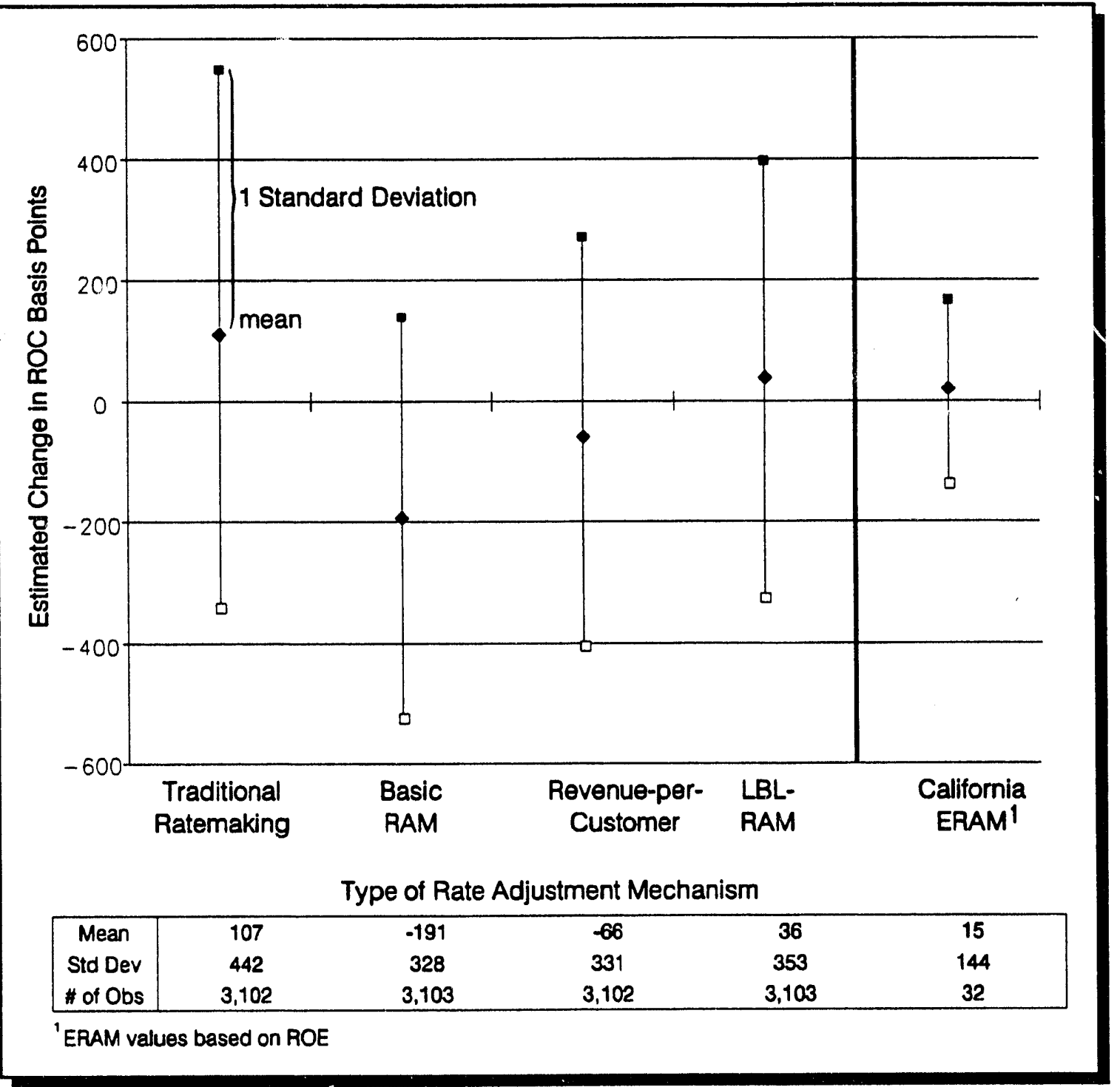

Figure EX-2 depicts expected incremental profit (above or below authorized profit) for each ratemaking scheme. To calculate these values, we simulated the different ratemaking processes using a historic test year and three year rate case cycle. In each case, authorized profit equals zero, reflecting a perfect match between revenue and cost (where cost includes capital expenses). The incremental profit depicted in this figure reflects the theoretical amount of revenue that would be allowed under each ratemaking scheme less actual expenses incurred. The California ERAM results reflect actual authorized revenue and actual expenses. 
previously determined analytically, that traditional ratemaking has, on average, a modest positive bias that increases profits between rate cases (since loads have been growing). In contrast, RPC has a small but negative bias that lowers profits on average (even though numbers of customers have also been growing). California's ERAM also has a slightly positive earnings bias, but with smaller variance, which we speculate is related to the detailed attrition underlying ERAM.

The variance we observe in these results is much greater than is the tendency of a given approach to bias profits in a particular direction. In other words, other factors, such as business practices, other regulations, and the general business climate, will likely have a greater influence on profits than will these specific ratemaking approaches.

What Have Been the Rate Impacts of Decoupling?

In the final section of the report, we consider the effect that decoupling has had on rate volatility and risk-shifting with a detailed review of the rate history of the electric utilities with the longest history of decoupling: Pacific Gas and Electric (PG\&E), Southern California Edison (SCE), and San Diego Gas and Electric (SDG\&E). ${ }^{3}$

We find that, for most California utilities, decoupling has actually reduced rate volatility compared to a situation in which there is no decoupling. ${ }^{4}$ Decoupling can in principle add to or counteract other sources of rate volatility and, in California, the net effect has been one of offsetting these other sources. Assessing the rate impacts of ERAM along with the other influences on rates also provides a basis for commenting on the magnitude of risk-shifting accounted for by ERAM. The record in California indicates that the riskshifting accounted for by ERAM is small or non-existent and, in any case, ERAM has contributed far less to rate volatility than have other adjustments to rates, such as the fuel-adjustment clause. See Table EX-1.

\footnotetext{
${ }^{3}$ Revenues for the Southern California Gas Company, as well as the gas departments of PG\&E and SDG\&E, are also partially decoupled (for core customers only) through an ERAM-like mechanism, but are not examined in this study.

${ }^{4}$ This approach to measuring the effect of ERAM on rates assumes that, without ERAM, the monies accrued in the ERAM balancing account would not otherwise be recognized through some other revenue adjustment, such as attrition or more frequent rate cases.
} 
Table EX-1. Annual Changes in Revenue Requirement and Retail Rates

\begin{tabular}{|c|c|c|c|c|c|c|}
\hline & \multicolumn{2}{|c|}{ PG\&E } & \multicolumn{2}{|c|}{ SCE } & \multicolumn{2}{|c|}{ SDG\&E } \\
\hline & $\begin{array}{c}\text { Rates } \\
\text { w/ERAM } \\
(\%)\end{array}$ & $\begin{array}{c}\text { Rates w/o } \\
\text { ERAM } \\
(\%)\end{array}$ & $\begin{array}{c}\text { Rates } \\
\text { w/ERAM } \\
(\%)\end{array}$ & $\begin{array}{c}\text { Rates w/o } \\
\text { ERAM } \\
(\%)\end{array}$ & $\begin{array}{l}\text { Rates } \\
\text { W/ERAM } \\
(\%)\end{array}$ & $\begin{array}{c}\text { Rates w/o } \\
\text { ERAM } \\
\text { (\%) }\end{array}$ \\
\hline Mean & 4.9 & 4.8 & 3.2 & 3.2 & -1.5 & -1.6 \\
\hline Std. Dev. & 7.5 & 9.6 & 7.7 & 7.5 & 7.4 & 7.9 \\
\hline
\end{tabular}

\section{Concluding Thoughts}

We believe there are three issues for utilities and regulators who are considering decoupling. First, the importance of lost revenues and therefore of decoupling depends strongly on pre-existing features of regulation. Foremost among these is the frequency of rate cases and the design of fuel adjustment clauses because they directly influence the size and persistence of the disincentives that decoupling seeks to address. At the same time, we also believe there are other incentives (and disincentives) for utilities to build load, which are distinct from the lost revenue problem. Regulatory reforms, therefore, should not focus exclusively on lost revenues, but instead take a broad perspective in trying to align utility incentives with the objectives of integrated resource planning.

Second, adoption of a decoupling mechanism requires consideration of the means by which revenues are set between rate cases, especially the means for accounting for changes in nonfuel costs. Our examination of the empirical record suggests that, over short periods of time, neither sales growth (which underlies traditional ratemaking) nor customer growth (which underlies RPC) provide a very powerful basis for explaining changes in these costs. In other words, the revenue-per-customer approach (in addition to decoupling sales from revenues) will on average do no worse than traditional ratemaking in recovering these costs. Thus, if cost-recovery is an important ratemaking objective, it is a separable concern from decoupling for which other approaches should be considered, such as attrition mechanisms or future test years.

Third, the record in California suggests that the issue of the additional rate volatility introduced by decoupling has been overemphasized. We believe that discussions of the additional rate volatility and risk-shifting associated with decoupling should be conducted in a framework that considers all sources of rate volatility and risk-shifting in ratemaking. In this framework, the questions of what the risks are and who is best suited 
to bear them can be made explicit and their treatment made comprehensive, rather than piecemeal.

Decoupling can play an important role in transforming utilities from sellers of a least-cost energy commodity to providers of least-cost energy services, but it is no panacea. While it can successfully eliminate an important disincentive for utility DSM programs, it must be designed carefully to take explicit account of other regulatory objectives, such as costrecovery and rate volatility. 


\section{Introduction}

Alfred Kahn once said "all regulation is incentive regulation." Ncwhere is the challenge that is implicit in this observation greater than in current debates about regulatory reforms in support of integrated resource planning. Integrated resource planning (IRP) requires that a utility consider all resource options for meeting customers' energy service needs in a consistent fashion. For both demand-side and nontraditional resources, questions have been raised about the appropriateness of traditional utility rate regulation for aligning utilities' earnings incentives with the goals of IRP (Moskovitz 1989).

Specific disincentives that have been noted for customer energy efficiency programs include: (1) utilities may not recover demand-side management (DSM) program expenses when these expenses have not been accounted for in some previous rate-setting process; (2) utilities may lose revenue from sales not made because of the success of customer energy efficiency programs; and (3) utilities may forego earnings opportunities because resources are devoted to DSM programs rather than to other profit-making activities (Nadel et al. 1992).

Various regulatory changes have been proposed to address these disincentives. Of these, decoupling, which addresses the issue of lost revenues, has been the subject of controversy. Decoupling refers to a class of automatic or semi-automatic annual ratemaking adjustments that ensure collection of an agreed-upon level of revenues independent of actual sales (Marnay and Comnes 1990).

Proponents argue that, without decoupling, a utility has powerful incentives to promote incremental sales and equally powerful disincentives to reduce sales growth through successful DSM programs (Moskovitz 1989). Proponents of decoupling have developed stylized examples indicating that incremental sales are highly profitable. Published quantifications of these findings include " 5 cents in profits for every additional $\mathrm{kWh}$ sold" (Moskovitz 1989) and " 130 basis points for a $1 \%$ increase in sales growth" (Hirst and Blank 1993).

According to this perspective, decoupling is required in order to make utilities indifferent to sales gains or losses and thereby to free utilities to promote customer energy efficiency programs, in order to achieve integrated resource planning objectives (Moskovitz and Swofford 1991). For this reason, proponents of decoupling also argue that decoupling 
is superior to net lost revenue adjustments ${ }^{5}$ because these adjustments deal only with revenue losses directly attributable to utility DSM activities while leaving the underlying incentive to make incremental sales unaffected (Moskovitz et al. 1992).

Opponents raise concerns about several aspects of decoupling. Some point out that promotion of incremental sales is not necessarily inconsistent with integrated resource planning (Tempchin 1993). However, while this judgement may be true, the problem addressed by decoupling is that these sales may be an unintended consequence of regulation, as opposed to an intended effect of regulatory policy (Moskovitz 1993).

Opponents also question the exact nature and size of the incentive for incremental sales and the ability of decoupling to mitigate this incentive. How universal are the stylized examples indicating highly profitable incremental sales? Moreover, how important is the profitability of incremental sales, so construed, relative to other profit-making opportunities available to the firm? This second issue has been identified as a specific limitation of decoupling because decoupling does not address other incentives in regulation, which span the rate case cycle (Binz 1992).

Concerns have also been raised that decoupling represents a form of automatic ratemaking (along with fuel adjustment clauses and some forms of attrition), so it could diminish the centrality of the rate case as the primary forum for examining (and contesting) utility practices, regulatory policies, and customer impacts. This issue is closely related to the previous one because the rate case has been the traditional forum for reviewing utility business activities. There are also specific questions regarding the ability of the Revenue-Per-Customer decoupling approach to track nonfuel expenses accurately (Chamberlin 1992).

Finally, there are concerns that decoupling, as implemented currently, may inappropriately shift business risks from utility shareholders to ratepayers, possibly leading to undesirable rate impacts. Indeed, concerns over rate impacts have led to reconsideration of decoupling in both Washington and Maine. One approach for addressing this concern has been the formulation of disaggregated sales models intended to more precisely allocate specific risks between ratepayers and shareholders (Hirst 1993). Yet another approach is to design cost-recovery policies that minimize year-toyear fluctuations in rate impacts (Mosiovitz et al. 1993). One hybrid approach involves invoking alternative procedures, which are triggered by the magnitude of expected rate impacts (Eachus 1993).

\footnotetext{
${ }^{5}$ Net lost revenue adjustments attempt to compensate utilities for revenues, less avoided production costs, lost from explicitly identified utility DSM programs (see Nadel et al. 1992).
} 
The goal of this report is to provide a broad framework in which to address these concerns. We have structured our work around three questions:

1) Why decouple? (Chapter 2)

2) How does decoupling work? (Chapters 3, 4, and 5)

3) What have been the rate impacts of decoupling? (Chapter 6)

In Chapter 2, we consider threshold issues for decoupling by characterizing precisely the underlying conditions leading to the profitability of incremental sales. The general methods we develop allow the reader to examine the relative profitability of incremental sales for a variety of circumstances. We also detail the limitations of our characterization and, therefore, of the utility's incentive for incremental sales. In a final section, we discuss a separate incremental sales incentive that decoupling does not address.

In Chapter 3, we examine how decoupling works by contrasting its operation with the traditional rate-setting process. We formalize our discussions with mathematical expressions to describe the rate-setting process more precisely. The discussions illustrate the relationships that regulation (with and without decoupling) establishes among sales, customer, and sales gi wth.

In Chapter 4, we examine some of the factors that have influenced nonfuel cost growth in the past; in the presence of fuel adjustment clauses, decoupling affects only the recovery of nonfuel costs. Our analysis is based on 25 years of annual financial statistics from 160 utilities representing about $80 \%$ of US electricity sales (FERC Form1). This examination provides an empirical basis for evaluating the relationships formalized in Chapter 3 and directly addresses issues raised by Moskovitz (1992) regarding the relationship between load growth versus customer growth on the one hand and nonfuel costs on the other.

In Chapter 5, we conduct a "what-if" evaluation of the performance of traditional, salescoupled rate regulation; two current decoupling revenue adjustment mechanisms, Revenue-Per-Customer and Electric Revenue Adjustment Mechanism (ERAM); and two additional, hypothetical decoupling approaches. The evaluation is based on simulating the performance of each ratemaking mechanism using our data set of historic utility costs, customers, and sales to determine the effect of each mechanism on utility profits and profit volatility. This evaluation provides a bottom line for the theoretical relationships established in Chapter 3 and the empirical record discussed in Chapter 4.

In Chapter 6, we review California's experience with ERAM. We complement previous work describing the mechanics of ERAM (Marnay and Comnes 1990) with information 
on the actual rate impacts experienced by California's major investor-owned electric utilities: Pacific Gas and Electric (PG\&E), Southern California Edison (SCE), and San Diego Gas and Electric (SDG\&E). In order to shed light on the risk-shifting impacts of ERAM, we quantify both the marginal and total impacts of ERAM in the context of the many rate adjustments experienced by California ratepayers during the past 14 years

In Chapter 7, we summarize our work by identifying issues for utilities and regulators to consider in evaluating the applicability of decoupling to their situations.

Four appendices follow. The first appendix describes the mathematical derivations underlying the calculation of between-rate-case profitability presented in Chapter 2 . The second appendix describes the FERC data used to the analyses presented in Chapters 4 and 5. The li.ird appendix complements the discussion in Chapter 4 with additional statistical analyses of the FERC data to identify better determinants of nonfuel costs. The fourth appendix complements the discussion in Chapter 6 with a formal quantification of the cost to consumers of risks associated with rate volatility. 


\section{How Does Traditional Ratemaking Influence the Profitability of Incremental Sales?}

This chapter considers the threshold question for decoupling: what are the incentives for incremental sales in traditional utility ratemaking? We begin by examining a commonly referenced characterization of the ratemaking process; this characterization focuses on the period between rate cases. For ease of presentation, we rely on a representative income statement for a composite utility in order to quantify the effects of additional revenues (from incremental sales) on utility profits. Our objective is to establish a framework for understanding the design and performance of the decoupling mechanisms that are discussed in subsequent chapters. We also consider the limitations of our characterization and, consequently, of decoupling as well. Demarcation of these limitations clarifies the differences between conflicting views on the ultimate effectiveness of decoupling in transforming utilities from sellers of an energy commodity to providers of energy services. ${ }^{6}$

\subsection{The Between-Rate-Case Incentive to Sell Electricity}

Table 2-1 presents a representative income statement for a composite utility: Revenues, for simplicity, are just sales multiplied by an average price. Average price has been fixed at 70 mills $/ \mathrm{kWh}$ and sales have been derived to yield an arbitrary total revenue of $\$ 100$. Costs consist of fuel, nonfuel O\&M, depreciation, interest, and taxes. Although these costs have been normalized to be consistent with a total revenue of $\$ 100$, the fractions of revenues that they represent reflect a composite of U.S. investor-owned utilities, as reported in the Energy Information Agency's most recent annual survey of utilities (Energy Information Administration (EIA) 1993).

Net income or profit is just the difference between revenues and costs. Net income can be expressed in several ways. For example, net income can be expressed as a percentage of total revenues, which can also be thought of as a profit margin, or as a return on equity, through specification of the capital structure of the utility. In this example, the initial situation of the utility, as represented in the first column of Table 2-1, indicates a profit margin of $10 \%$ and a return on equity of $12 \%$.

${ }^{6}$ See Krause and Eto (1988) for an articulation of the rationale for this transformation. 
Table 2-1. Profitability of $1 \%$ Sales Increase Without Decoupling Examples

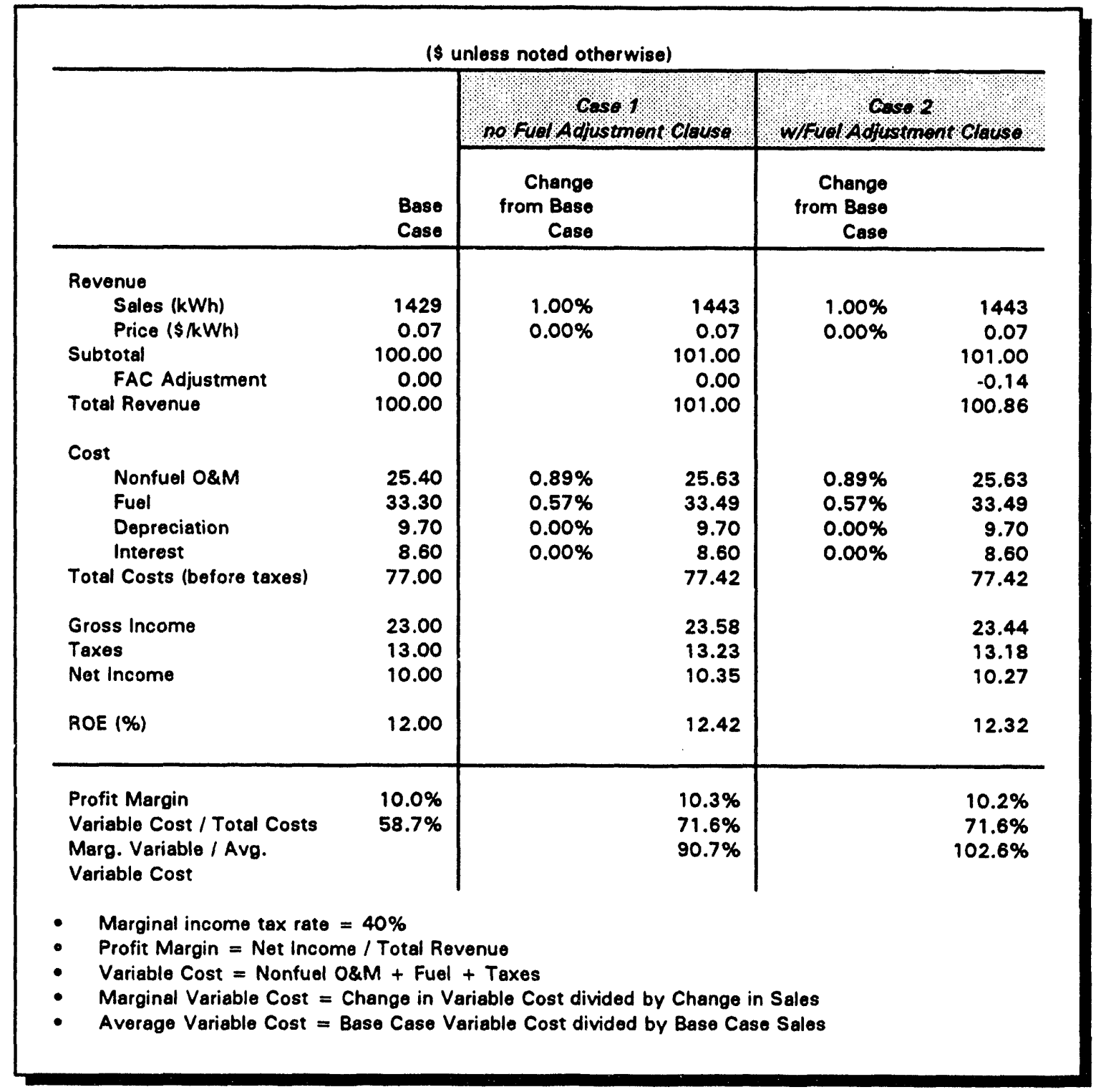


In the first change case, we consider how profits would be affected by a $1 \%$ increase in sales. ${ }^{7}$ Marginal revenue is assumeci to equal average revenue, which is to say that, in the short term (i.e., before the next rate case), the price of electricity is fixed and is assumed to be linear. ${ }^{8}$ As a result, a $1 \%$ increase in sales leads to a $1 \%$ increase in revenue.

However, marginal cost is not equal to average cost. Not all costs are directly affected by changes in sales. Interest, depreciation, and some portion of nonfuel O\&M are costs that are unlikely to vary in the very short run as a result of changes in sales and are in this sense fixed. Fuel, and some portion of nonfuel O\&M costs, on the other hand, are likely to be influenced by sales and are in this sense variable. If gross income changes, taxes will also be affected. ${ }^{9}$ In our example, these variable costs (fuel, nonfuel O\&M, and taxes) account for nearly $60 \%$ of total costs.

The costs that do change in response to changes in sales can vary greatly. Marginal variable costs can either exceed or be less than average variable costs. For the two most recent, consecutive years of utility financial information in our data set (1987 and 1988), marginal variable costs (MVC) due to a $1 \%$ increase in electricity sales have been slightly more than $70 \%$ of average variable costs (AVC). ${ }^{10}$ In other words, marginal costs are less than average costs. The aggregate change consists of the weighted average of an $89 \%$ change in MVC to AVC for nonfuel O\&M costs ${ }^{11}$ and a $57 \%$ change in MVC to AVC for fuel, plus taxes..

Marginal profitability is the difference between marginal revenues and marginal costs. Net income and return on equity increase by almost $4 \%$. Expressed as a change in basis points from an initial return on equity of $12 \%$, the effect works out to be about 40 basis points or less than $\$ 0.03$ per $\mathrm{kWh}$ of incremental sales.

'As will be clear in this chapter and Appendix A, all of the examples can be viewed from the perspective of the impacts of either a percentage increase in sales or a percentage decrease in sales.

${ }^{8} \mathrm{Many}$ tariffs, in fact, are non-linear. Examples include block rates, time-of-use rates, demand charges, and customer charges. For the purposes of this example, we suppress these subtleties of rate design.

9 Corporate tax strategies are very complicated. For simplicity, onr examples assume that the incremental tax rate is $40 \%$.

10 The data set, which consists of 25 consecutive years of FERC form=1 information from over 160 investor-owned utilities, is described in Appendix A.

"For this example, we have adopted a simplifying convention in which all observed changes in costs are expressed in terms of a change in sales. In fact, some of these costs are fixed and some change in response to things other than sales; we take up some of these issues in Chapter 4. 
Case 2 presents the same example in the presence of a stylized fuel adjustment clause. In this example, fuel costs are fully decoupled from the sales increase. ${ }^{12}$ We represent this situation by showing a current year debit to income statement for the difference between average and marginal fuel expenses. In fact, fuel costs would increase this year, but their effect on earnings would be offset by a future year rate increase whose present value would exactly offset this year's fuel cost increase. That is, excess fuel costs would accrue in a fuel balancing account and would not affect the company's income statement.

The effect of this characterization of a fuel adjustment clause is to eliminate the influence of changes in fuel costs on the relationship between marginal variable cost and average variable cost. The variable cost fraction is unchanged, but the resulting relationship between MVC and AVC increases to about $95 \%$ (up from $71 \%$ in case 1). In this situation (with marginal fuel costs less than average fuel costs), a $1 \%$ increase in sales now translates to a more than 50 basis-point increase in return on equity.

Clearly, these results are just reflections of the specific assumptions made regarding the magnitude of the affected cost elements as fractions of total cost, the rate of change of these cost elements compared to changes in sales, and the level of profits at the start. For these examples, the assumptions reflect historic, composite industry conditions.

Fortunately, it is straightforward to generalize from these specific assumptions to treat all possible situations. Appendix A contains the mathematics underlying this generalization, in the remainder of this section, we present the results and their implications.

Figure 2-1 illustrates the relationship between a $1 \%$ increase in sales and the resulting increase (or decrease) in profit. The results are presented for three levels of variable costs as a fraction of total costs $(40 \%, 60 \%$, and $80 \%)$, which are represented by three downward-sloping horizontal lines. For each of these situations, alternative marginalto-average variable cost relationships are represented along the horizontal axis. The resulting change in profit, expressed as a change in return on equity, normalized to an initial $12 \%$, is seen on the vertical axis. The situations described for cases 1 and 2 from the previous examples are indicated.

Figure 2-1 indicates that the profitability of an increase in sales goes up: 1) as the variable cost fraction of total costs decreases because a larger fraction of costs is fixed;

12 The design of fuel adjustment clauses can vary widely. This example represents the typical case in which all differences in per-unit fuel costs from the base case accrue in a balancing account. 
Figure 2-1. Profitability of $1 \%$ Sales Increase

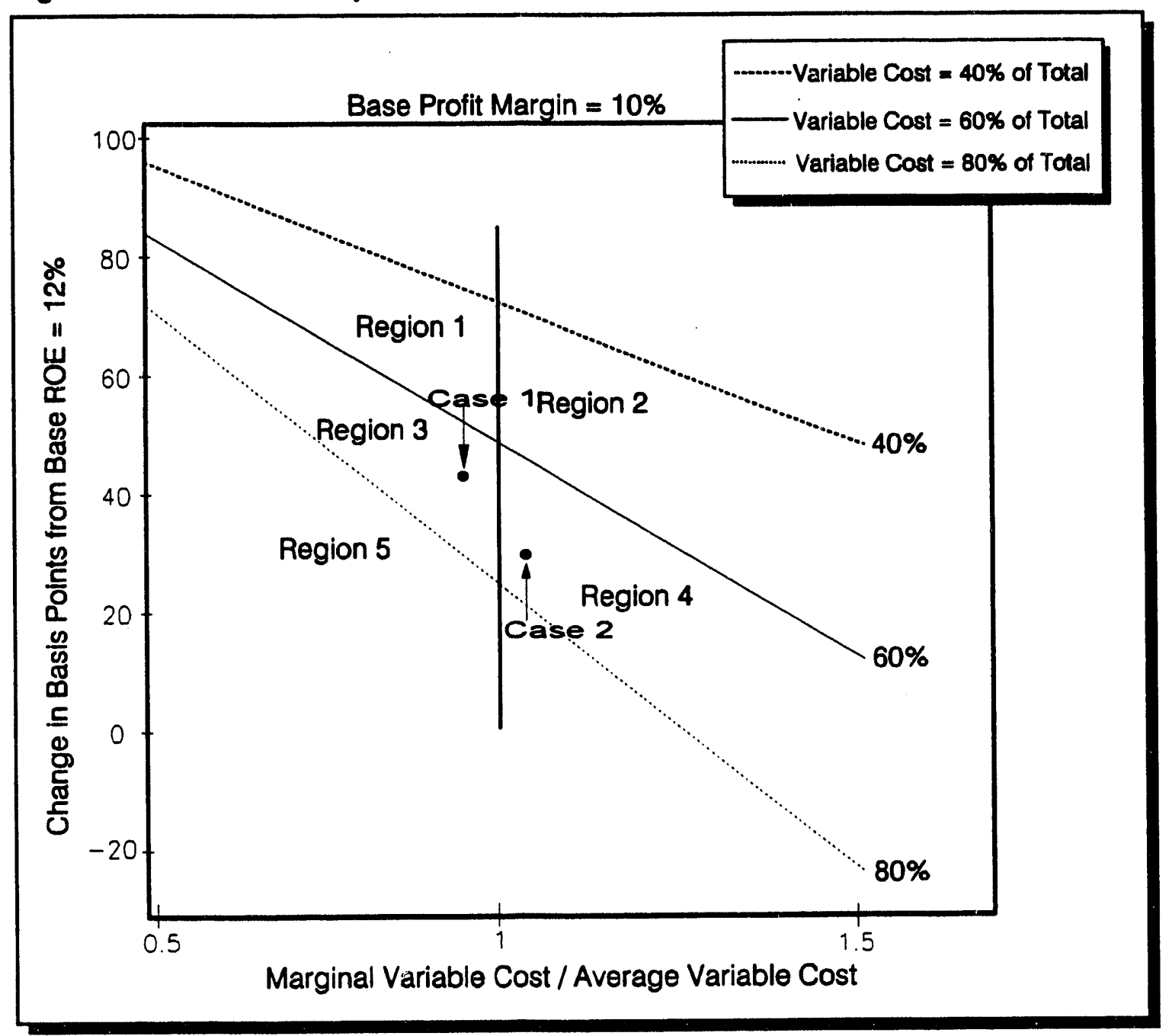

Figure 2-1 illustrates the relationship between a $1 \%$ increase in sales and the resulting increase (or decrease) in profit. The results are presented for three levels of variable costs as a fraction of total costs $(40 \%, 60 \%$ and $80 \%$ ), which are represented by three downward-sloping horizontal lines. Alternative marginal variable to average variable cost relationships are represented along the horizontal axis. The resulting change in profit, expressed as a change in return on equity, normalized to an initial 12\%, is depicted on the vertical axis. Using FERC Form-1 data from 1987 and 1988, we mapped the current cost structure of U.S. electric utilities onto this graph. Of the 122 utilities examined, 33\% are in Region 1, 20\% are in Region 2, 31\% are in Region 3, 12\% are in Region 4, and 4\% are in Region 5. This graph indicates that, when prices are fixed, there are very few situations in which increased sales cannot lead to increased profits. See text for discussion of Cases 1 and 2. 
and 2) as the responsiveness of these costs (marginal variable-to-average variable costs) to increases in sales decreases. ${ }^{13}$

Table 2-2 summarizes the cost structure of the utilities examined in this report. The table identifies five cost structure regimes for utilities from the most recent year in our data set: utilities with variable cost fractions between 40 and $60 \%$ (53\% of utilities), 60 and $80 \%$ ( $31 \%$ of utilities), and in excess of $80 \%$ (3\% of utilities); and utilities with marginal variable over average variable costs equal to or in excess of one $(32 \%$ of utilities), and less than one (68\% of utilities). These regimes are also indicated on Figure 2-1.

\section{Table 2-2. Cost Structure of U.S. Investor-Owned Electric Utilities}

\begin{tabular}{l|c|c|c}
\hline \multirow{2}{*}{$\begin{array}{l}\text { Variable Cost/ } \\
\text { Total Cost }\end{array}$} & \multicolumn{3}{|c}{ Marginal Variable/Average Variable Cost } \\
\cline { 2 - 4 } & $<1$ & $>$ or $=1$ & Total \\
\hline $40-60 \%$ & $33 \%^{1}$ & $20 \%^{2}$ & $53 \%$ \\
\hline $60-80 \%$ & $31 \%^{3}$ & $12 \%^{4}$ & $43 \%$ \\
\hline $80-100 \%$ & $4 \%^{5}$ & & $4 \%$ \\
\hline \hline Total & $68 \%$ & $32 \%$ & $100 \%$
\end{tabular}

'designated as Region 1 on Figure 2-1

2 designated as Region 2 on Figure $2-1$

3 designatod as Region 3 on Figure 2-1

4 designated as îegion 4 on Figure 2-1

5 designates as Rogion 5 on Figure 2-1

Based on 1987 and 1988 FERC Form-1 data for 122 utilities

Taken together, Table 2-2 and Figure 2-1 indicate that, when prices are fixed and linear, there are very few situations in which increased sales cannot lead to increased profits. First, only a fraction of the total cost of production will be affected by increases in sales. Second, the degree to which these costs are affected must exceed by a wide margin the

${ }^{13}$ The relationships illustrated on Figure 2-1 are also affected by the initial profit margin, which was assumed to be $10 \%$. We show, in Appendix $A$, that the general conclusions are robust for a range of initial profit margins (See Figure A-1). 
percentage increase in sales in order to offset the increase in revenues from sales. That is, for the broad range of conditions characterizing the cost structure of the electric industry today ( 40 to $80 \%$ of total costs being affected by a change in sales), costs must increase by a factor of two to three times the percentage increase in sales. If costs do not increase this sharply in response to changes in sales, increased sales will always lead to increased profits.

\subsection{The Rate Case is a Limit to this Incentive}

The profitability of increased sales described in the previous section depends on two critical assumptions: 1) retail rates are fixed and linear so that marginal revenue is equal to average revenue, and 2) some fraction of costs are fixed and therefore marginal costs are usually less than average costs. In this section, we consider the ways in which rate cases limit the consequences of these assumptions.

During rate cases, fixed and variable costs are considered simultaneously. Adjustments are made to the rate base, a rate-of-return is determined, operating and other expenses are considered, and sales are used to set rates. Although there are important procedural differences between states that rely on historic test years versus future test years for this process, the outcome is similar: rates are established that apply until they are revised.

The object of a rate case is to realign the cost relationships that underlie the profitability of incremental sales examined in the previous section. For example, a rate case can prospectively restore earnings opportunities deemed to have fallen inappropriately because of reduced sales or increased costs.

In other words, rate cases act to limit the continuing efficacy of the conditions (described previously) that make incremental sales profitable. In this regard, the profitability of incremental sales appears to be a direct consequence of regulatory lag under the current cost conditions faced by the industry.

Figure 2-2 presents some basic information on the frequency of rate cases. The information was developed by reviewing 10 years of Public Utilities Fortnightly to determine the historic frequency of rate cases. Based on reports for nearly 160 rate cases, we find the average time between rate cases from 1984 to 1992 has been about three years, with the median being slightly less.

The implication for decoupling is clear: if the incentive to sell additional electricity described in the previous section is the primary incentive addressed by decoupling, the importance of decoupling depends on the frequency of rate cases. Because rate cases 
Figure 2-2. The Rate Case as a Limit to the Profitability of Sales Increases

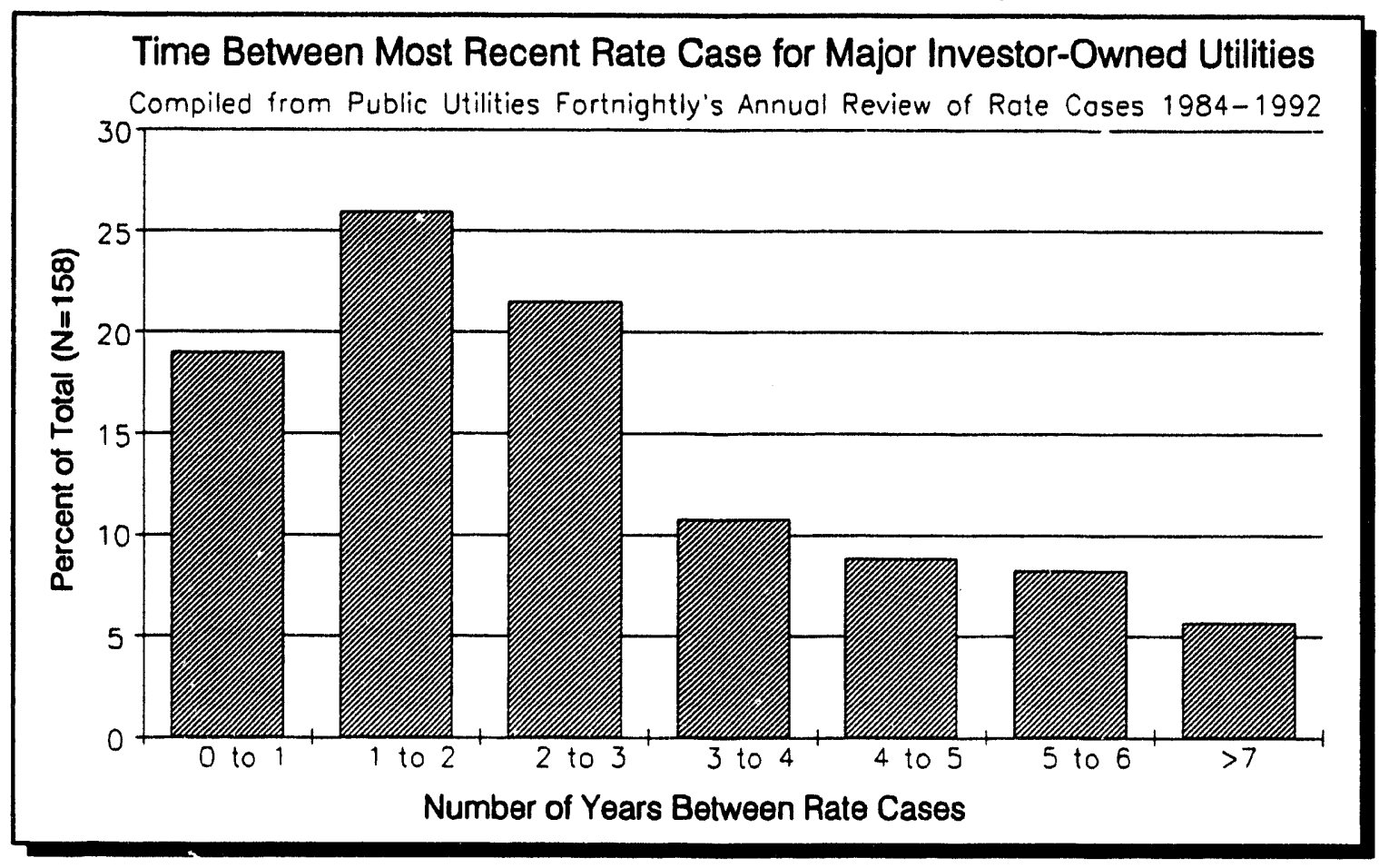

can, in principle, fully address all issues underlying the short-run profitability of incremental sales, the value of an additional regulatory intervention, such as decoupling, probably diminishes with increased rate case frequency.

Nevertheless, more frequent rate cases simply to address this aspect of regulatory lag is unlikely to be a viable option because they are time-consuming and expensive to hold. Moreover, to the extent utilities control the timing of rate cases, they may be reluctant to subject all aspects of their business to detailed scrutiny by regulators, particularly so if their business is excessively profitable. Indeed, cost changes that in the past have led to more frequent rate cases have in turn led to the creation of "automatic" adjustment clauses (of which fuel adjustment clauses are the most well-known example), which try to deal directly with specific cost changes, without requiring a rate case. The history of recent regulatory practice has been to create a variety of out-of-rate-case procedures precisely to ensure that rate cases will not be held more frequently. In this regard, 
decoupling may be desirable because, to the extent it can successfully address changing costs that would otherwise lead to rate cases, it may delay the need for a rate case. ${ }^{14}$

\subsection{The Other Incentive to Sell Electricity}

Section 2.1 demonstrated how regulatory lag creates an incentive for incremental sales between rate cases. Section 2.2 identified some of the practical limitations of having more frequent rate cases in order to reduce regulatory lag, thereby creating a role for ratemaking reforms such as decoupling. However, we believe there may be other incentives (and disincentives) for incremental sales that are distinct from that currently created by regulatory lag. Understanding the significance of these incentives is a final threshold issue for decoupling.

Rate-of-return regulation creates a shareholder incentive for utilities to build rate base whenever the rate-of-return exceeds the cost of capital. This feature of regulation is known as the Averch-Johnson thesis. ${ }^{15}$ One purpose of the rate case, which recognizes this tendency, is to provide a periodic check on a utilities' activities to ensure that additions to the rate base are prudent. However, the purpose of the rate case is not to question the wisdom of basing utility rates on formulas that link authorized earnings to a fixed percentage of undepreciated assets. If building rate base to meet increased loads leads to increases in authorizeu revenues and also increases profits, then the basic formulation of rate-of-return regulation creates a distinct incentive for incremental sales.

However, increases in authorized revenues may not translate automatically into increases in profits. Building rate base generally requires new capital. On the one hand, the increased cost of debt may not be fully covered by the authorized increase in earnings. That is, the basic premise of the Averch-Johnson thesis, that the rate-of-return exceeds the cost of capital, may no longer be true. In this situation, if additional shares must be sold to raise capital, shareholder equity will be diluted and, other things being equal, earnings per share will drop. In addition, individual project returns and the size of the firm combine to influence the profitability of individual rate base additions. ${ }^{16}$

\footnotetext{
14 In the Chapter 3, we will describe specifically how decoupling, in fact, leads to reintroduction of some aspects of a rate case because of the way in which it shifts the focus of regulation from rate-setting to revenuesetting. In the Chapters 4 and 5, we will examine how well decoupling deals with cost recovery between rate cases and the resulting effect on profits.

is See, for example, Train (1991) for a recent treatment of this topic.

${ }^{16}$ See, for example, Jeynes (1968) for the classic treatment of this topic.
} 
More fundamentally, it also depends on one's view of the future of the investor-owned utility industry. If additions to generating plant cost more than historic average costs, rates will increase. Depending on the options available to utility customers (i.e., their price elasticity of demand), rate increases could have disproportionate effects on future sales and hence earnings. Finally, in world where utilities do very little of the building of new generation, the continuing relevance of an incentive to build load needs to be reexamined.

We cannot treat these issues adequately in the current report. Our point is merely to suggest that there may be other incentives for utilities build load in addition to the one created by regulatory lag. While we have identified rate-of-return regulation as possibly being one such incentive, there are likely to be others. A systematic treatment of decoupling requires, at a minimum, consideration of these incentives. If their influence is small, they may be ignored. If their influence is large, then whether they serve to reinforce or mitigate the incentives created by regulatory lag will become more important.

We show in subsequent chapters that decoupling is, in fact, neutral on the issue of how big the rate base and the sales base that underlies it should be. In this regard, we believe that decoupling is broadly consistent with integrated resource planning because it makes the utility indifferent to incremental sales or losses between rate cases. However, another forum (such as a rate case) must then address the larger questions about the appropriate level of sales and size of the rate base.

\subsection{Summary}

All firms have an incentive to sell more of their product and a disincentive to sell less whenever the marginal revenue (MR) from a sale exceeds the marginal cost (MC) of production. These conditions (MR $>M C$ ) are generally reflective of the current revenue stream and cost structure of most utilities today. For regulated utilities, however, the strength of the incentive to sell and therefore the ability of decoupling to address this. incentive depends on other features of regulation. Foremost among these is the frequency of rate cases and the design of fuel adjustment clauses because they directly influence the size and persistence of the disincentives that decoupling seeks to address. At the same time, we also believe there are other incentives (and disincentives) for utilities to build load, which are distinct from the lost revenue problem. Regulatory reforms, therefore, should not focus exclusively on lost revenues, but instead take a broad perspective in trying to align utility incentives with the objectives of integrated resource planning. 


\section{Decoupling Revenue Adjustment Mechanisms}

This chapter explains the relationship between traditional utility ratemaking and decoupling. In the first section, we describe the process of establishing a revenue requirement and the setting of rates under traditional rate-of-return regulation. This section includes a discussion of the general rate case, attrition, and automatic adjustment clauses. In the second section, we examine the ways decoupling is used within this traditional process of regulation. We begin by showing how use of a balancing account breaks the link between sales and revenue by ensuring the exact collection of an authorized revenue over time. We then explain how decoupling mechanisms work in conjunction with between-rate-case adjustments to authorized revenues in order to prevent earnings attrition. Finally, we formally define and contrast the decoupling mechanisms that are in use in California, Maine, New York, and Washington.

\subsection{Ratemaking Fundamentals}

In this section, we describe the general process of ratemaking that is used to regulate electric utilities in most states today. First, we explain how the revenue requirement, allocation of revenue between customer classes, and rate design are determined in a general rate case. Next, we describe how the revenue requirement and rates are adjusted between rate cases through automatic adjustment clauses and attrition hearings. We draw from AGA/EEI Introduction to Public Utility Accounting for much of this material (American Gas Association (AGA) 1992). Readers familiar with this subject may wish to skip to 3.2 .

\subsubsection{The General Rate Case}

\section{Test Year}

The first step in a general rate case is to develop a representative cost of service that reflects jurisdictional sales, revenues, operating and maintenance expenses, depreciation expenses, income taxes, and return-on-rate base. Although the ratemaking process is forward-looking (i.e., rates are being set to take effect for the year following the rate case), most jurisdictions use a historical test year to calculate the cost of service or revenue requirement. The most commonly identified advantage of the historic test year over a future or forecasted test year is the conservatism inherent in basing future rates 
on a known and measurable standard of costs, which of course is most readily documented using recorded costs. However, this advantage is ambiguous because it is customary to adjust recorded figures, in both historic and future test year jurisdictions, to reflect current and expected cost levels and to normalize unusual or erratic expenses.

\section{Revenue Requirement}

The different test year costs are combined to develop a revenue requirement. The revenue requirement is defined as:

$$
R=O M+\text { Fuel }+ \text { Capital Expenses + Taxes }
$$

- O\&M includes generation, transmission, distribution, and administrative costs.

- Fuel includes fossil fuel, nuclear fuel, water for power, and purchased power expenses.

- Capital expenses include return on rate base and depreciation. Rate base, broadly defined, is the value of used and useful capital assets (after depreciation). The rate-of-return should reflect the cost of the capital that was used to obtain the rate base assets. Depreciation is a non-cash expense that reflects the loss of value of tangible assets over time.

Price

For historic test years, price is calculated by dividing the historic test year's revenue requirement by historic sales.

$$
P=\frac{R^{h}}{Q^{h}}
$$

For utilities that use a future test year, historic values are replaced with forecasts.

$$
P=\frac{\hat{R}}{\hat{Q}}
$$

The price that is set in the general rate case is used until there is either 1) another general rate case, or 2) a between-rate-case adjustment. 


\section{Actual Revenue and Profit}

The revenue requirement, defined above, is a hypothetical value that represents the amount of revenue assumed necessary for the utility to cover its expenses and provide a fair return to investors. Actual revenues are a function of price, as established in the general rate case, and actual sales. Accordingly, the revenue requirement and actual revenues will differ to the extent that actual sales differ from the sales quantity used in the general rate case. Profit is equal to actual revenues minus actual expenses.

\subsubsection{Between-Rate-Case Adjustments}

There are many types of between-rate-case proceedings or regulatory mechanisms that change the revenue requirement and rates. Most of these changes can be classified as automatic adjustment clauses or attrition adjustments. While many states have some form of automatic adjustment clause, substantially fewer states use attrition adjustments.

Generally, an automatic adjustment clause (AAC) is a rate provision which allows a utility: (1) to identify changes in specific operating costs above and below a base cost which is a permanent part of the rate structure; and (2) to pass increases (or decreases) in these costs on to consumers through a surcharge or credit to the bill without complex or time-consuming administrative or legal procedures.

There are two types of automatic adjustment clauses. The first retroactively reconciles actual expenditures and revenue. The fuel adjustment clause (FAC) is the most important of this type because it is widely used (in $\mathbf{4 0}$ states) and has a large impact on rates. The second type prospectively adjusts rates based on readily available historic or forecast data. Inflation adjustments to O\&M expenses fall into this category. Many states have inflation adjustment clauses which update the revenue requirement's O\&M expense using some type of regional or national inflation index.

Attrition is "the erosion of earnings that will result when costs are increasing more rapidly than revenues" (Radford 1992). Double-digit inflation and a decreasing rate of sales growth during the 1970's heightened utility interest in between-rate-case financial and operational attrition adjustments. Financial attrition adjustments compensate for increases in capital-related expenses including additions to rate base and higher financing costs. Operational attrition adjustments compensate for increases in operation and maintenance expenses and increased fuel costs (in those jurisdictions without an FAC). Although both types of attrition items were subject to adjustments, the focus of any given attrition adjustment was typically on a single item (unlike a rate case in which all costs are subject to examination). 
Attrition adjustments, in those states which permit their use, affect the revenue requirement and rates in much the same way as prospective automatic adjustment clauses. Automatic adjustment clauses are usually specified in advance and based on objective, publicly available information because they are used to track costs which are outside the utility's control and which are known to fluctuate, such as fuel and purchase power costs. In contrast, attrition adjustments require the utility to document the necessity for a change in the revenue requirement.

\subsection{Decoupling Revenue Adjustment Mechanisms}

Traditional rate-of-return regulation and decoupling use the general rate case and between-rate-case adjustments to establish a revenue requirement. Under traditional ratemaking procedures, the revenue requirement almost always differs from actual revenue because of fluctuations in sales. Decoupling ensures that actual revenues exactly match an established revenue requirement, regardless of the sales level. To reflect this important nuance, we refer to the revenue requirement that is established under decoupling as the authorized revenue.

Every decoupling Revenue Adjustment Mechanism, or RAM, consists of two parts. First, all decoupling RAMs use balancing accounts to guarantee the exact collection of authorized revenue over time. Second, all decoupling RAMs work in conjunction with an explicit method for changing the level of authorized revenue during years between general rate cases.

\subsubsection{Breaking the Link Between Sales and Revenue Using a Balancing Account}

The use of a balancing account to ensure exact collection of authorized revenue is consistent in all revenue decoupling RAMs and is central to removing bias against conservation. We begin our explication of the different decoupling RAMs by describing a simplified decoupling mechanism which embodies only this first feature. We assume that this decoupling mechanism, which we call the "Basic" Rate Adjustment Mechanism, operates in a state with a two-year general rate case cycle and no other between-rate-case revenue adjustments. Table 3-1 illustrates the Basic RAM:

The basic RAM requires three sets of numbers to track revenue and price. Columns A-C are established in the general rate case and remain fixed until the next general rate case. Columns D-F represent what actually occurs during each year. Columns G-I represent the numbers that the utility reports in its financial statements (income statement and balance sheet). 
Table 3-1. Basic RAM Example

\begin{tabular}{|c|c|c|c|c|c|c|c|c|c|c|}
\hline & & A & B & C & D & $E$ & $F$ & $\mathbf{G}$ & H & 1 \\
\hline & & $\begin{array}{c}\text { Expected } \\
\text { Price } \\
\$ / \mathrm{kWh} \\
\end{array}$ & $\begin{array}{l}\text { Expoctod } \\
\text { Salos } \\
\text { kWh }\end{array}$ & $\begin{array}{c}\text { Authorized } \\
\text { Rov } \\
4\end{array}$ & $\begin{array}{l}\text { Price } \\
\text { / kWh }\end{array}$ & $\begin{array}{l}\text { Colloctod } \\
\text { Sales } \\
\text { kWh }\end{array}$ & $\begin{array}{c}\text { Revenue } \\
\$\end{array}$ & $\begin{array}{c}\text { Reported } \\
\text { Revenue } \\
8\end{array}$ & $\begin{array}{c}+1 . \\
8\end{array}$ & $\begin{array}{c}\text { Balence } \\
\text { Account } \\
6 \\
\end{array}$ \\
\hline GRC 1 & $\begin{array}{l}\text { Yr } 1 \\
\text { Yr } 2\end{array}$ & $\begin{array}{l}0.100 \\
0.100\end{array}$ & $\begin{array}{l}1000 \\
1000\end{array}$ & $\begin{array}{l}100.00 \\
100.00\end{array}$ & $\begin{array}{l}0.100 \\
0.090\end{array}$ & $\begin{array}{r}1100 \\
990\end{array}$ & $\begin{array}{r}110.00 \\
89.10\end{array}$ & $\begin{array}{l}100.00 \\
100.00\end{array}$ & $\begin{array}{c}10.00 \\
(10.90)\end{array}$ & $\begin{array}{c}(10.00) \\
0.90\end{array}$ \\
\hline GRC 2 & Yr 3 & 0.110 & 1010 & 111.10 & 0.111 & 1010 & 112.00 & 111.10 & 0.90 & 0.00 \\
\hline
\end{tabular}

Examining how the numbers change from year to year illustrates how the Basic RAM operates:

\section{Year 1}

General Rate Case \#1 (GRC 1) authorizes revenue of $\$ 100$ based on expected sales of $1,000 \mathrm{kWh}$. During the year, the utility sells $1,100 \mathrm{kWh}$ at $\$ 0.10 / \mathrm{kWh}$, resulting in "Collected Revenue" of $\$ 110$. Basic RAM ensures that the utility can only keep the "Authorized Revenue" of $\$ 100$. Thus, "Reported Revenue" equals $\$ 100$ and $-\$ 10$ is placed into a balancing account. Negative values in the balancing account indicate money that the utility owes the ratepayers (accounts payable); positive values indicate money that ratepayers owe the utility (accounts receivable).

\section{Year 2}

Authorized revenue of $\$ 100$ and expected sales of $1,000 \mathrm{kWh}$ are still in effect from GRC 1. In addition, the utility must "retum" $\$ 10$ to ratepayers from the previous year's overcollection. Accordingly, if the utility collects $\$ 90$ this year, it will be even with the ratepayers. Thus, the Year 2 Price of $\$ 0.09 / \mathrm{kWh}$ is calculated by dividing the total revenue that the utility wants to collect $(\$ 90)$ by expected sales (still 1,000 kWh). However, in this case the utility sold less power than expected, resulting in collected revenue of $\$ 89.10$. The utility still reports revenue of $\$ 100$, which covers the $\$ 89.10$ collected from ratepayers this year, the $\$ 10$ extra that was collected from ratepayers last year, and $\$ 0.90$ that appears in the balancing account, representing money that the ratepayers owe the utility. 


\section{Year 3}

As a result of General Rate Case \#2 (GRC 2), authorized revenue has increased to $\$ 111.10$ based on expected sales of $1,010 \mathrm{kWh}$. In addition, the utility is allowed to collect $\$ 0.90$ from ratepayers because of the previous year's shortfall. Accordingly, if the utility collects $\$ 112$ this year, it will be even with the ratepayers. Thus, the Year 3 Price of $\$ 0.111 / \mathrm{kWh}$ cents is calculated by dividing the total revenue that the utility wants to collect $(\$ 112)$ by the expected sales (now $1,010 \mathrm{kWh}$ ). As it turns out, actual sales match expected sales, resulting in collected revenues of $\$ 112$. The utility reports revenue of $\$ 111.10$ for Year 3, and the difference in the balancing account $(\$ 0.90)$ means the utility has recovered the previous year's shortfall.

In order to make the Basic RAM simple to understand, we have suppressed the interest component of the balancing account and matched Year 3's expected and actual sales. The balancing account's interest rate is usually pegged to the cost of short-term debt (although some states use the utility's weighted average cost of capital). To the extent that the two rates differ, the utility could be motivated to increase or decrease the decoupling balance. In our analysis, we assume that the interest rate on the balancing account and the cost of funding the balancing account are the same, eliminating the motivation to game the balancing account.

\subsubsection{The Need for Changes in Authorized Revenue Between Rate Cases}

In our simple example, we showed how balancing accounts ensure that authorized revenues are collected over time. However, in the example we assumed that authorized revenue remained fixed between general rate cases. This is an unrealistic assumption if expenses increase from year to year while revenues remain fixed. As we illustrated in Chapter 2, the problem may become more severe as the time between general rate cases increases. Under traditional rate-of-return regulation, additional revenue associated with increased sales offsets growth in expenses. Decoupling regulations address the problem of increasing expenses by making specific changes to the authorized revenue in years between rate cases. Although balancing accounts operate the same in all decoupling mechanisms, each decoupling mechanism has a unique method for making between-ratecase changes to authorized revenue. These differences are discussed in the next section. In Chapters 4 and 5, we examine the consequences of these differences empirically. 


\subsection{A Look at Specific Decoupling RAMs}

Decoupling Revenue Adjustment Mechanisms are currently used in California, New York, Maine, and Washington. California and New York developed decoupling RAMs that rely on already established procedures for adjusting the revenue requirement between general rate cases. In contrast, Maine and Washington developed new procedures for adjusting authorized revenue between general rate cases. The precise formulation of these procedures is described below.

\subsubsection{California ERAM}

Revenue decoupling was implemented in California in 1982 by CPUC, Dec. 82-12-055 (California Public Utilities Commission (CPUC) 1981). The stated purpose of California's Electric Revenue Adjustment Mechanism (ERAM) “is to adjust base rate (non-fuel) revenues for changes in revenues due to unexpected fluctuations in sales during the test period." Purported advantages of ERAM include: 1) it affords a utility a better opportunity to earn its authorized rate of return, 2) it eliminates disincentives for the utility to promote conservation, and 3 ) it stimulates innovative rate design. ${ }^{17}$ Currently, all regulated electric and gas utilities in California are subject to ERAM, including Pacific Gas and Electric (PG\&E), Southern California Edison (SCE), San Diego Electric and Gas (SDG\&E), and Southern California Gas (SCG).

California sets rates and revenue using a future test year and a three-year general rate case cycle. Accordingly, the authorized revenue is based on assumptions about what will happen in subsequent years. The following is a definition of authorized revenue, as determined in the triennial general rate case:

$$
R^{a}=\frac{\hat{C}}{\hat{Q}} \cdot \hat{Q}=\hat{C}
$$

where $R^{a}$ indicates authorized revenue, $\hat{C}$ indicates forecast nonfuel cost, and $\hat{Q}$ indicates forecast sales.

When ERAM was implemented, California was already using a variety of between-ratecase revenue adjustment techniques, which it continues to use with ERAM, including an attrition rate adjustment (ARA), cost-of-capital proceedings, and a fuel adjustment clause.

17 The history, mechanics, and policy issues of California's ERAM have been well documented (Marnay 1990). Our object in this discussion is to review and contrast its specification with other decoupling approaches. In Chapter 6, we summarize the rate impacts of California ERAM. 
Under ARA, authorized revenue is escalated using both recorded and forecast escalation factors for labor and nonlabor operation expenses. These escalation factors assume that cost increases associated with sales and customer growth are offset by increased productivity. Additions to the rate base also are addressed by the ARA. Changes in the adopted rate of return are addressed separately in the annual cost of capital proceeding. California also has used a number of ad hoc between-rate-case adjustments associated with major construction projects such as the Diablo Canyon and San Onofre nuclear generating stations.

Rather than develop new methods for adjusting authorized revenue, California's regulators rely on the existing methods for adjusting the revenue requirement. Thus, the authorized revenue for a given year is expressed as

$$
R^{a t}=\hat{C}+\sum_{i=1}^{n} A
$$

where $t$ is the number of years since the last general rate case, $n$ is the total number of years between rate cases, and $A$ includes all adjustments to authorized revenue.

Using information from the balancing account discussion above and our authorized revenue equation, we can now calculate a system average price for a given year:

$$
P^{\prime}=\frac{R^{a t}+B^{t-1}}{\hat{Q}}
$$

where $P^{t}$ indicates price in year $t, B^{t-1}$ indicates the amount in the ERAM balancing account at the end of the previous year, and $\hat{Q}$ is the sales forecast for year $t$.

\subsubsection{New York Revenue Decoupling Mechanism}

In 1988, the New York Public Service Commission ordered New York utilities to propose ratemaking innovations that would align the interests of utility shareholders and customers. The Commission's goal was to provide customers with the benefits of leastcost planning and DSM using a mechanism that would also be beneficial to utility shareholders. As part of this reform process, Orange and Rockland adopted an ERAMlike revenue decoupling mechanism (RDM) in 1991 to remove the bias against energy conservation (DiValentino et al. 1992). Since that time, some form of this decoupling has been adopted by all New York utilities, except Central Hudson. Like California, New York is a future-test-year jurisdiction with a tradition of multi-staged revenue filings in which base rates are set and adjusted periodically to reflect changes in specific costs. 
RDM was implemented in conjunction with a provision for annual changes in authorized revenue to recover increases in the cost of providing services over a three year rate plan. Adjustments are provided for fuel, operation and maintenance expenses, rate base investment, and the cost of senior capital. Most O\&M expenses are subject to an inflation attrition allowance based on a forecast GNP price deflator index. Authorized revenue is updated annually to reflect forecast additions to net utility plant investment and related increases in depreciation. Changes in the utilities' capital structure and cost of debt and preferred stock are updated annually. These changes are reviewed by the New York Public Service Commission through petitions and other required filings.

Although the exact techniques used to adjust authorized revenue are different in New York and California, both provide for between-rate-case adjustments to reflect changes in fuel expenses, O\&M expenses, rate base, capital structure, and cost of senior capital. In contrast, California adjusts the adopted return on equity annually while New York fixes it between general rate cases. Despite these differences, the structure of decoupling mechanisms used in the two states is essentially the same.

\subsubsection{Maine and Washington Revenue-Per-Customer}

In 1991 Puget Power (Moskovitz and Swofford 1991) and Central Maine Power (Goldfard and Spellman 1993) adopted decoupling revenue adjustment mechanisms. According to the agreements authorized by Commissions in Washington and Maine, general rate cases would proceed according to current methods, and the timing of rate cases would continue to be on an "as needed" basis. The new regulations would decouple revenue from sales and recouple revenue to the number of customers. This decoupling revenue adjustment mechanism, called Revenue-Per-Customer (RPC), requires two calculation:s. First, authorized revenue per customer, which remains fixed until the next general rate case, is computed by dividing allowed revenues $\left(R^{h}\right)$ by the number of customers $\left(N^{h}\right)$, as determined in a historic test-year rate case:

$$
R P C^{h}=\frac{R^{h}}{N^{h}}
$$

Second, authorized revenue for a given year $t$ is computed by multiplying the authorized revenue per customer times the number of customers $\left(N^{\natural}\right)$ :

$$
R^{a t}=R P C^{h} \cdot N^{t}
$$

After each year, the difference between collected revenue and authorized revenue is placed in a balancing account. The following year's rates are adjusted to refund/collect the over/undercollected balance. 
Maine and Washington's RPC mechanisms are nearly identical because both decouple revenue from sales and recouple revenue to customers. However, prior to implementing RPC, Puget Power did not have an adjustment clause (with which this hydro-based utility would recover costs for a variety of resources, not only fuel). Now, Puget Power recovers fuel, purchased power (including hydro), and conservation costs through an annual adjustment mechanism that operates in conjunction with RPC. Maine, in contrast, already had a fuel adjustment clause, which remained in effect after the implementation of RPC.

\subsection{Summary}

In this chapter we have examined differences among traditional rate of return regulation and decoupling mechanisms used in California, Maine, New York, and Washington. The table below identifies important characteristics of each type of regulation.

Table 3-2. Comparison of Ratemaking Approaches

\begin{tabular}{|c|c|c|c|}
\hline & $\begin{array}{c}\text { Decouples } \\
\text { Revenue From } \\
\text { Sales }\end{array}$ & $\begin{array}{l}\text { Authorized } \\
\text { Between-Rate- } \\
\text { Case Revenue } \\
\text { Adjustments }\end{array}$ & $\begin{array}{c}\text { Fuel } \\
\text { Adjustment } \\
\text { Clause }\end{array}$ \\
\hline Traditional Ratemaking & No & $\begin{array}{l}\text { Limited attrition, } \\
\text { in a few states }\end{array}$ & $\begin{array}{l}\text { Yes, in most } \\
\text { states }\end{array}$ \\
\hline California's ERAM & Yes & $\begin{array}{l}\text { Detailed attrition } \\
\text { procedures }\end{array}$ & Yes \\
\hline New York's RDM & Yes & $\begin{array}{l}\text { Broad attrition } \\
\text { procedures }\end{array}$ & Yes \\
\hline Maine's RPC & Yes & $\#$ of customers & Yes \\
\hline Washington's RPC & Yes & \# of customers & $\begin{array}{l}\text { Yes, reintroduced } \\
\text { with RPC }\end{array}$ \\
\hline
\end{tabular}

A primary issue for both traditional ratemaking and decoupling is the appropriateness of these explicit and implicit forms of adjusting revenues between rate cases. In Chapters 4 and 5, we will examine the appropriateness of the formal relationships established in this chapter to track non-fuel costs in order to evaluate the consequences of these ratemaking procedures on utility profits. 


\section{Sales Versus Customers as Determinants of Nonfuel Costs}

In this chapter, we examine the use of sales versus number of customers as an alternative means for recovering utility costs. In the presence of a fuel adjustment clause, the issue becomes: how closely are changes in nonfuel costs related either to changes in sales (which is how current rate regulation allows utilities to recover these costs) or to some alternative (such as the ones embodied in decoupling mechanisms)? An important issue for RPC is whether recoupling revenues to customer growth improves or reduces a utility's ability to recover these costs (between rate cases) versus the way in which they are recovered under traditional ratemaking. In this chapter, we restrict our focus to the cost-recovery assumptions inherent in traditional ratemaking and RPC decoupling because cost-recovery for California ERAM and New York RDM are linked to attrition mechanisms that have been established separately (and due to their complexity are difficult to evaluate).

The first section of this chapter introduces the data used in our analysis. A more detailed description of the data and its preparation for analysis is presented in Appendix B. In the second section, we present our findings on the ability of changes in sales and customers to explain changes in nonfuel costs. This discussion, however, considers only the ability of one-year changes in load and customers to explain changes in nonfuel costs. Appendix $\mathrm{C}$ presents additional exploratory analyses considering different formulations of these explanatory variables, as well as others. ${ }^{18}$

\subsection{Aggregate Utility Data on Sales, Customers, and Costs}

The U.S. electric power industry is a combination of private, public, cooperative, and federal utilities. Private or investor-owned electric utilities account for more than threefourths of the revenues and sales in the industry and have historically served large consolidated markets. The Federal Energy Regulatory Commission (FERC) gathers information annually on "major" private electric utilities on Form-1. Major private electric utilities are defined as private utilities that have during the previous past three

\footnotetext{
${ }^{18}$ In this chapter, we only consider the way in which traditional ratemaking and the RPC decoupling approach allow utilities to recover costs. In Chapter 5, we examine the resulting profit implications of traditional ratemaking and the various decoupling approaches.
} 
consecutive calendar years had sales or transmission services that exceeded one of the following:

- 1 million megawatthours of total annual sales;

- 100 megawatthours of annual sales for resale;

- 500 megawatthours of annual gross interchange out; or

- 500 megawatthours of wheeling for others.

We obtained selected information from Form-1, covering the years 1964 to 1988, for 160 reporting utilities for a total of 3,278 observations. Appendix B provides background on the choice of this data set as well as a description of the steps involved in preparing the data for analysis.

\subsubsection{Definition of Sales, Customers, Costs, and Capitalization}

In this section, we describe the construction of regression variables used both in this chapter and later in Chapter 5. Although the customer and sales data were readily available, constructing nonfuel cost and capital levels required quite a bit of data manipulation. We used the GDP price deflator found in The Economic Report of the President - February 1991 to change nominal dollars into real 1982 dollars (Council of Economic Advisors 1992).

\section{Customers and Sales}

In our regression models, we use the independent variables "Total Ultimate Customers" and "Total Sales to Ultimate Customers." The following classes are included in this group:

- Residential

- Commercial and Industrial

- Public Street and Highway lighting

- Other to Public Authorities

- Railroads and Railways

- Interdepartmental 


\section{NonFuel Costs}

Nonfuel costs include operation and maintenance, capital, and tax expenses. Below, we list the major components of each type of expense:

\section{Operation \& Maintenance Expense}

- Steam power production less fuel

- Nuclear power production less fuel

- Hydraulic power production less water for power

- Other power production less fuel

- Other power supply less purchased power

- Transmission

- Distribution

- Administration

\section{Capital Expense}

- Net interest charges times the ratio of electric plant to total utility plant

- Preferred stock dividend times the ratio of electric plant to total utility plant

- Common stock dividend times the ratio of electric plant to total utility plant

- Depreciation of electric plant

- Amortization of electric plant

- Taxes

\section{Capitalization}

From the balance sheet, we constructed electric utility capital:

- Common stock (book value) times the ratio of electric plant to total utility plant

- Preferred stock (book value) times the ratio of electric plant to total utility plant

- Other Paid-in Capital

- Retained earnings

- Miscellaneous small capital accounts

- Total long-term debt times the ratio of electric plant to total utility plant 
Figure 4-1. Uses of Revenue for Major Investor-Owned Electric Utilities

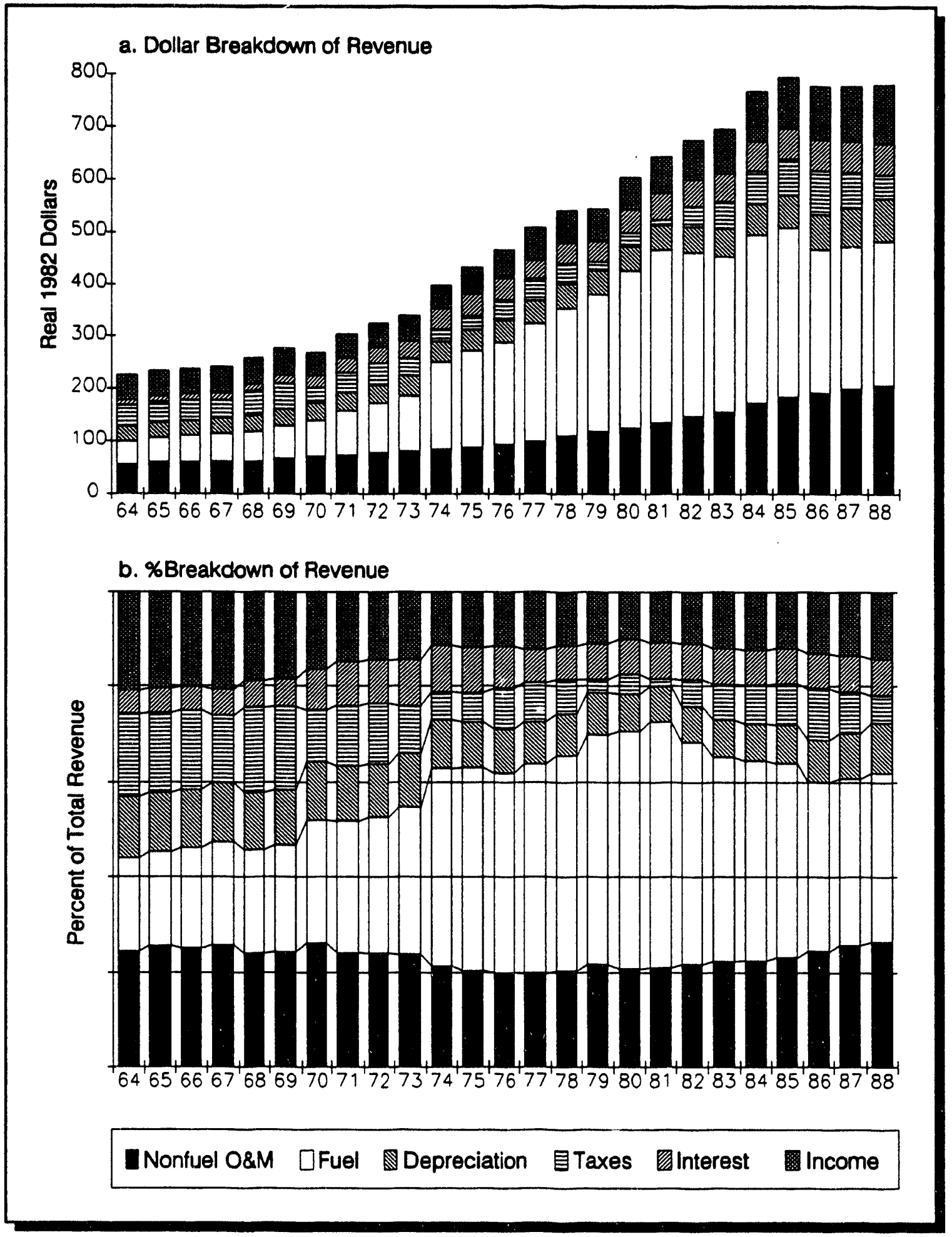




\subsubsection{Summary of Data}

Figure 4-1 summarizes the aggregate data over time. Nonfuel cost has been split into its major components.

\subsection{Regression Analysis of Selected Determinants of Nonfuel Costs}

Electric utility regulation implicitly or explicitly establishes relationships among nonfuel costs, sales, and numbers of customers. We have designed several regression models to examine the historic relationship among these three variables. In doing so, we hope to provide insight into how well these relationships correspond to actual utility operation. We begin by formulating algebraically the relationships we will examine statistically. We then report our findings.

\subsubsection{Sales and Customers as Determinants of Nonfuel Cost Changes}

Traditional ratemaking and the revenue-per-customer decoupling approach can be modeled as

$$
R_{t}=R_{h} \frac{S_{t}}{S_{h}} \quad \text { and } \quad R_{t}=R_{h} \frac{N_{t}}{N_{h}}
$$

where $R$ is revenue, $S$ is sales, and $N$ is the number of customers. The subscript $t$ refers to the current period, while $h$ refers to the test year. Because we believe that both $S$ and $N$ influence nonfuel costs, we need incorporate both into a single equation for purposes of estimation. By algebraically rewriting these relationships, it becomes apparent how to proceed:

$$
R_{t}=R_{h}+R_{h}\left[\frac{S_{t}}{S_{h}}-1\right] \quad \text { and } \quad R_{t}=R_{h}+R_{h}\left[\frac{N_{t}}{N_{h}}-1\right]
$$

Now we can adjust $R_{t}$ separately for these two percentage changes. Finally, let us also include the possibility that $R_{t}$ may be a weighted average of $S$ and $N$ and that $R_{t}$ may grow autonomously. We now have a more general model:

$$
R_{t}=R_{h} \cdot \beta^{t-h}+R_{h} \cdot \beta_{1}\left[\frac{S_{t}}{S_{h}}-1\right]+R_{h} \cdot \beta_{2}\left[\frac{N_{t}}{N_{h}}-1\right]
$$


which we now simplify to the single period case $(t=h+1)$, subtract $R_{h}$ from both sides, and divide by $R_{h}$. Note that the terms in brackets are just the percentage changes in $S$ and $N$ respectively; when $t=h+1$, we will call these $\% \Delta S$ and $\% \Delta N$ :

$$
\frac{R_{t}-R_{h}}{R_{h}}=\frac{R_{h} \cdot \beta+R_{h} \cdot \beta_{1} \% \Delta S+R_{h} \cdot \beta_{2} \% \Delta S-R_{h}}{R_{h}}
$$

Remembering that nonfuel revenues should equal nonfuel costs because we have defined costs to include the allowed rate of return, we rewrite the last equation in terms of nonfuel cost and add the standard regression error term, $\epsilon$ :

$$
\% \Delta C=\beta_{0}+\beta_{1} \cdot \% \Delta S+\beta_{2} \cdot \% \Delta N+\epsilon
$$

where $\% \Delta C$ indicates the percentage change in nonfuel cost for one year and $\beta_{0}=$ $\beta-1$.

\subsubsection{Regression Results}

We now run several regressions, most of which are specific cases of Equation 4-1 above: two with sales, two with customers, and one with both plus an autonomous trend. These help us evaluate traditional ratemaking, RPC, and a final, potentially less biased Revenue Adjustment Mechanism. Each of these regressions is run on approximately 3,300 data points from the FERC data set.

The sales regression yields:

$$
\% \Delta C=\underset{(24.5)}{0.399} \cdot \% \Delta S \quad R^{2}=0.15
$$

where the number in parentheses refers to the t-statistic associated with the regression coefficient estimate. This result says that only $40 \%$ of a change in sales is correlated with a 100\% change in nonfuel costs. This should be compared to traditional ratemaking, which is based on the implicit assumption that

$$
\% \Delta C=1.0 \cdot \% \Delta S
$$

which says that every change in sales perfectly $(100 \%)$ correlates with changes in nonfuel costs. Though it appears that traditional rate regulation provides significant rewards in the short run to utilities that have typical sales growth, this model suppresses any effects of increased sales on long-term costs. (See also Appendix C).

We need to run one more regression with sales in order to find the true incentive for load building. This regression includes an intercept or constant term, as follows: 


$$
\% \Delta C=\underset{(20.1)}{0.032}+\underset{(4.6)}{0.099} \% \frac{\pi S}{R^{2}=0.01}
$$

This regression shows that the change in cost of $0.399 \% \Delta S$ discovered in the previous regression was not caused solely by $\% \Delta S$ but was simply associated with it. Thus, if a utility deliberately achieved a higher $\% \Delta S$, it would probably expect this change to be associated with a cost increase $10 \%$ as great instead of $40 \%$ as great as the extra change in $\% \Delta S$. Thus, the cost of load-building is quite low, and the compensation from traditional ratemaking is $90 \%$ in excess of this cost. ${ }^{19}$

Next, we turn to a regression involving the number of customers, in order to examine the basic assumption underlying the revenue-per-customer decoupling approach. We again begin with the regression without a constant term. The estimated version of this regression is:

$$
\% \Delta C=0.725 \cdot \% \Delta N \quad R^{2}=0.14
$$

We see that, on average, RPC overrewards by somewhat more than can be observed in the historic data (compare 1.0 to 0.72 ).

We need to run one more regression with customers in order to find the true relationship between customer and nonfuel cost growth. This regression includes an intercept or constant term, as follows:

$$
\% \Delta C=0.030+0.294 \cdot \% \Delta N \quad R^{2}=0.02
$$

This second customer regression shows that the change in cost of $0.725 \% \Delta N$ from the previous regression was mostly not caused by $\% \Delta N$ but was simply associated with it. The cost of serving additional customers is substantially lower, as evidenced by the second regression's coefficient of $0.294 \% \Delta N$.

Finally, we present a comprehensive regression reflected in Equation 4-1, which considers all three influences simultaneously. In addition to the inclusion of a number of customers and a constant, we specify a sales-related term in the form of sales-per-

\footnotetext{
19 Even this estimate of the incentive is too high because we should have looked at the effect of sales-percustomer on costs instead of the effect of sales on costs.
} 
customer (SPC) ${ }^{20}$ This regrcssion yields the following coefficients, standard errors and $\mathbf{R}^{2}$ :

$$
\% \Delta C=0.029+0.035 \cdot \% \Delta S P C+0.305 \cdot \% \Delta N \quad R^{2}=0.02
$$

As can be seen, the effect of a $1 \%$ change in the number of customers is roughly nine times larger than the effect of a similar change in sales-per-customer (compare 0.305 to 0.035).

Although the effect of customers (compared to sales-per-customers or the constant term) is substantial on average, it is important to note the extremely low $R^{2}$ of this regression. Such a low $R^{2}$ does not indicate that the effect of customers or sales-per-customer is either poorly estimated or small; instead, it simply indicates that other strong effects have been omitted from our regression. Some of these omitted effects are undoubtedly idiosyncratic, others may be factors that might be addressed explicitly through attrition adjustments (such as interest rates).

Appendix C summarizes additional regression models that further explore effects of sales and customers on nonfuel costs. We also examine the impact of adding attrition-related variables such as capital level, interest rates, and economic growth.

\subsection{Summary}

Our results show that one-year changes in the number of customers have a fairly strong one-year impact on nonfuel costs but that one-year changes in sales have a rather weak effect. Nevertheless, the results show that, even after accounting for the effects of these two variables and the autonomous trend or constant term, the vast majority of the yearto-year variation in nonfuel costs remain unexplained. In other words, neither the traditional basis for adjusting revenues to account for changes in nonfuel costs nor that embodied in RPC does a very good job of tracking these costs. Between the two approaches, RPC does slightly better.

${ }^{20}$ Simply including sales would be inappropriate because some sales growth is already accounted for by the number of customers. Sales-per-customer allows us to estimate the residual sales-driven costs separately from those that are driven by the number of customers. 


\section{Evaluation of Decoupling Revenue Adjustment Mechanisms}

In principle, decoupling should not, solely by its operation, generate earnings beyond those provided for in the rate case. That is, incremental profits should result from increased utility operational efficiencies, rather than from artifacts of the revenue-setting process. In reality, incremental profitability will be determined by how well the revenuesetting mechanism embodied in a decoupling approach tracks underlying cost changes. In Chapter 4, we began investigating this issue by examining how well customer and load growth tracked these costs. In this chapter, we complete our investigation by using the FERC Form-1 data to conduct a controlled experiment measuring the relative, incremental profitability of several alternative decoupling approaches. Similarly, we also examine the historic profitability of California's ERAM.

\subsection{Four Decoupling Revenue Adjustment Mechanisms}

Decoupling Revenue Adjustment Mechanisms (or RAM's) differ only in their approach to revenue-setting. We consider four approaches: (1) a Basic RAM, without any type of attrition, which will serve as a benchmark; ${ }^{21}$ (2) the Revenue-Per-Customer approach or RPC; (3) a hypothetical RAM, based on the final regression presented in Chapter 4, which includes both customers, load-per-customer, and a constant term (called LBLRAM); and (4) California's ERAM. We also examine a characterization of traditional ratemaking, in which prices are held fixed. Table 5-1 summarizes the differences among the revenue-setting approaches.

\subsection{Evaluation of RAM Performance}

The incremental profitability of the three hypothetical RAMs and of traditional ratemaking all can be examined systematically using the FERC Form-1 data set. The basic approach is to develop models of the operation of the RAMs, implement them in a standardized fashion, and then calculate the differences between actual and modeled nonfuel revenues.

${ }^{21}$ This simplistic (and highly unlikely) revenue-setting approach was the basis for the example presented in Chapter 3. 
Table 5-1. Comparison of Revenue-Setting Approaches

\begin{tabular}{ll}
\hline $\begin{array}{l}\text { Revenue Adjustment } \\
\text { Mechanism }\end{array}$ & $\begin{array}{l}\text { Approach to Setting } \\
\text { Revenues }\end{array}$ \\
\hline Traditional Ratemaking & $C_{N} / S_{n}$ times actual sales \\
Basic RAM & Authorized Revenue in Test Year \\
Revenue-Per-Customer & $C_{N} / N_{n}$ times actual \# of customers \\
LBL RAM & see equation in text, section 5.2 .4 \\
California ERAM & Authorized revenue (test or attrition year) \\
& \\
\hline
\end{tabular}

We implement the approach in three steps: First, we pick a historic test year. In that year, we compute the revenue $R_{h}$ that would be necessary to cover all nonfuel costs $C_{h}$, including the allowed rate of return. By including the cost of capital, we have included all economic costs and, therefore, $R_{h}-C_{h}$ is equal to economic profit and is zero by definition in the test year. Second, we develop $R$ and $C$ for the following three years, which we fix to be the standardized length of time before the next rate case. Costs for these years are simply those reported in the FERC data set. Revenues are computed to be $R_{h}$ plus whatever attrition correction is appropriate for the RAM in question. Third, once we have $R$ and $C$, we compute profit as the difference between the two.

The profit calculated by this approach is properly thought of as incremental profit. It is a (possibly) unintended profit earned, in addition to that established in the rate case, solely as a result of the decoupling revenue-setting process and actual cost changes between rate cases.

We then normalized incremental profit to capital for each revenue-setting approach in order to compare results across utilities and over time. We report both expected profit and the variability of profit. The results are presented in Figure 5-1. The zero line represents the situation in which no excess profits (losses) are earned. It corresponds to a situation in which actual earnings equal those assumed in the rate-setting process.

This general approach was used to evaluate all of the revenue-setting approaches except ERAM. California's ERAM depends crucially on a very complex attrition mechanism which, even if modeled, could not be evaluated with the FERC form 1 data. Consequently we have had to evaluate this type of RAM simply by analyzing its performance when applied to the three California electric utilities for a period of ten 
Figure 5-1. Profitability of Traditional Ratemaking and Decoupling Revenue Adjustment Mechanisms

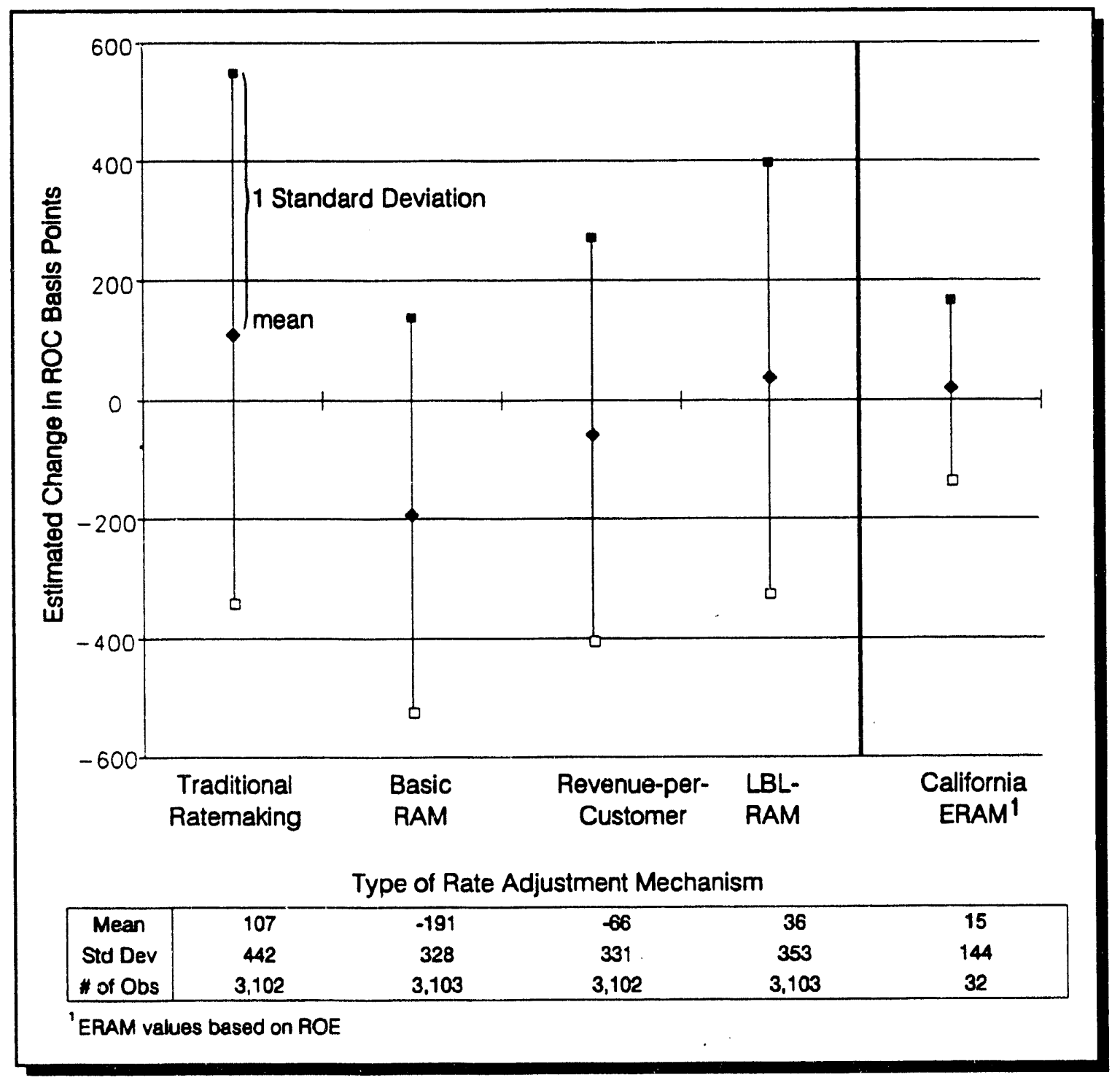

Figure 5-1 depicts expected incremental profit (above or below authorized profit) for each ratemaking scheme. To calculate these values, we simulated the different ratemaking processes using a historic test year and three year rate case cycle. In each case, authorized profit equals zero, reflecting a perfect match between revenue and cost (where cost includes capital expenses). The incremental profit depicted in this figure reflects the theoretical amount of revenue that would be allowed under each ratemaking scheme less actual expenses incurred. The California ERAM results reflect actual authorized revenue and actual expenses. 
years. Specifically, the ERAM results are based on actual profit levels. Southern Califormia Edison, San Diego Gas \& Electric, and Pacific Gas \& Electric provided us with actual and authorized profit from 1983 to 1992, which covers the entire time that ERAM has been in existence. We calculated economic profit by subtracting authorized return on equity, which is determined in annual rate proceedings, from actual return on equity. For California ERAM, we report the average and standard deviation of the 30 economic profit values (three utilities with ten years of performance data). Finally, we were only able to obtain information on return-on-equity. Because capital is larger than equity, the ERAM results presented would probably have a mean even closer to zero, had it been possible to normalize economic profit to capital.

\subsubsection{Traditional Ratemaking}

Traditional ratemaking holds the nonfuel component of prices fixed between rate cases. To mimic this with FERC data, we compute ${ }_{R_{h}}^{R_{h}} \bar{Q}_{t}$ fuel revenue $t$ years after a rate case as
follows:

This fixes price at the historic level indicated by the historic test year and produces incremental annual profits of nearly 110 basis points. The fact that profit is consistently high indicates that during this time period costs must on average have been falling relative to prices. This is, in effect, a confirmation that the cost conditions leading to profitable incremental sales (described in Chapter 2) were prevalent during this time period.

Also, as can be seen in Figure 5-1, the variance in profit is the largest of the five revenue-setting approaches considered. The standard deviation is in fact more than four times larger than the estimated positive bias.

\subsubsection{Basic RAM}

Basic RAM without any form of attrition is even simpler to analyze. It simply sets $R_{t}$ $=R_{h}$. This does not allow revenue to increase with either the number of customers, load or with anything else. Because both have increased historically and because they cause cost increases, Basic RAM causes a large profit loss. This loss is estimated to be almost 200 basis points. However, the variance around this result is even greater, although not as large as that found for traditional ratemaking. 
This most basic form of a decoupling RAM has not been and is not likely to be implemented, but it is interesting to see why it should not be, and it is useful as a benchmark against which to judge the various RAMs that include explicit revenue adjustments. For example, the result confirms that costs did tend to rise in the period between rate cases. On the other hand, these costs did not rise as fast as marginal revenue under traditional ratemaking.

\subsubsection{Revenue-per-Customer}

The revenue-per-customer or RPC decoupling revenue adjustment mechan ism allows revenues to grow in proportion to the number of customers. Thus, if $N_{h}$ is the number of customers in the historic test year, and $N_{t}$ is the number in year $t$, then

$$
R_{t}=\frac{R_{h}}{N_{h}} N_{t}
$$

Notice that this takes the same form as the revenue-setting mechanism used in traditional rate regulation, except that number of customers replaces sales. Because customers seem to have much more of an impact on short-run cost than do sales per customer (see Chapter 4), we would expect this RAM to be only slightly less profitable than traditional rate regulation, which includes both effects. As indicated in Figure 5-1, revenue-percustomer does indeed perform much better than does Basic RAM, producing a profit loss of slightly less than 70 basis points. The variance is comparable to that of the other approaches (except ERAM); in other words, much larger than the negative bias.

\subsubsection{LBL RAM}

In Chapter 4, we estimated a regression equation that included the combined effects on nonfuel costs of changes in sales per customer and the number of customers. We found that the effect is less than proportional in both cases, so neither traditional ratemaking nor RPC makes an optimal attrition adjustment. That is, from the standpoint of a regression, traditional ratemaking assumes a coefficient on load growth of 1.0 with no constant or intercept term, while RPC assumes a coefficient of 1.0 on customer growth with no intercept. We now construct a RAM that should completely remove the profit bias, and, as a byproduct, should also tend to reduce the variance of profit:

$$
R_{t}=R_{h} \cdot\left[(1.03)^{t}+0.04 \cdot\left(\frac{L P C_{t}}{L P C_{h}}-1\right)+0.31 \cdot\left(\frac{N_{t}}{N_{h}}-1\right)\right]
$$


As can be seen, this RAM also uses a constant exogenous growth rate (or intercept) to help account for nonfuel costs. Figure 5-1 indicates that LBL-RAM has the lowest bias of any of the revenue-setting mechanisms (except ERAM). The incremental profit associated with this approach is less than 40 basis points. Nevertheless, the variance is comparable to that of the other RAMs.

\subsubsection{California's ERAM}

California's ERAM can be thought of as a basic RAM with a complex nonfuel cost index providing for attrition. Thus, we might write it as:

$$
R_{t}=\frac{R_{h}}{C_{h}} C_{t}
$$

where $C$ is the cost index. This does not explain much and, in fact, it is very difficult to give a meaningful quick summary of the attrition adjustment, but it should be noted that the adjustment does take into account the number of customers. ${ }^{22}$

Figure 5-1 shows how ERAM performed between 1983 and 1992 for the three major California electric utilities: PG\&E, SDG\&E, and SoCal Electric. The attrition approach underlying the ERAM adjustment mechanism appears to measurably reduce the bias and variance, as compared to the other revenue-setting approaches. Nevertheless, there is still a measurable positive bias of approximately 15 basis points. ${ }^{23}$

Bear in mind, however, that the performance of ERAM was calculated in a very different fashion than that used for the other RAMs. These differences severely limit our ability to compare the results of ERAM directly to that of the other RAMs.

\subsection{Summary}

We saw previously (in Chapter 3) that any RAM, even the most basic, is sufficient to eliminate the utility's incentive to build load. ${ }^{24}$ The issue for decoupling is, without the use of load to establish revenues, how should revenues be established? This chapter has

${ }^{2}$ Marnay (1990) describes the elements of California's attrition in great detail.

${ }^{23}$ As noted previously (in Section 5.2), since we were able to estimate the profitability of ERAM based only on return on equity, so we believe the estimated bias is higher than it would be if we had used return on capital.

${ }^{24}$ This is true when load is not one of the variables used to set authorized revenues between rate cases. 
considered this issue from the standpoint of the bias and variability of incremental profits resulting from adoption of several revenue-setting approaches. The results were developed using a standardized procedure that allowed comparison to traditional ratemaking.

We first demonstrated that the most basic RAM, without any attrition mechanism, introduces a significant downward bias in profit. Any of several attrition alternatives can greatly reduce this bias, but they must contain some adjustment for customer growth. We also found that our characterization of traditional ratemaking, which adjusts revenues in direct proportion to sales, also led to a reduction in bias. Finally, although correcting for customer growth is sufficient to eliminate most of the bias introduced by a basic RAM, it is does not eliminate much of the variance in profit that is present with or without a RAM.

All of the results were subject to wide variability. The smallest variability was observed in the historic performance of California's ERAM. This finding, with some qualifications, should not be surprising because the attrition adjustments underlying California's ERAM are very disaggregated and complex while the equivalent adjustments we have considered were restricted to sales, customers, and an exogenous trend or constant term. One would expect a more detailed tracking of components of nonfuel costs (that also includes customer growth) would perform more accurately than an aggregate tracking of these costs based only on sales or customer growth.

More importantly, the variance we observe in these results is much greater than is the tendency of a given approach to bias profits in a particular direction. In other words, other factors, such as business practices, other regulations, and the general business climate, will likely have a greater influence on profits than will these specific ratemaking approaches. 


\section{The Historic Rate Impacts of ERAM in California}

Much of the current controversy surrounding decoupling has centered on its rate impacts, which arise as a consequence of the balancing account required to implement decoupling. The issues range from philosophical implications of risk-shifting to pragmatic concerns regarding the magnitude of the accrued balances and their potentially dramatic impacts on rates. The goal of this chapter is to provide a context for these discussions by introducing the historic record of decoupling from the state with the longest experience with decoupling, California. Appendix D continues this discussion with a theoretical quantification of the risk-shifting implications of decoupling.

\subsection{Tracing the History of ERAM in California}

As has been well-documented in Marnay and Comnes (1990), California ratemaking is a complicated process. Rates are adjusted both through triennial general rate cases (GRC) and through a variety of annual adjustments, of which ERAM is only one. Annually, there is also a fuel adjustment clause (referred to as the Energy Cost Adjustment Clause) and an attrition adjustment, in addition to several other less-wellknown or less-systematically-used adjustments. Retail rates reflect the net impact of all of these adjustments.

The primary challenge for documenting the rate impacts of ERAM was identification of a consistent set of records. We ultimately determined that, wherever possible, we would rely on publicly available rate decisions on file at the California Public Utilities Commission (CPUC). Nevertheless, we were not able to locate decisions for several years and thus have relied on company-supplied data in some cases.

We obtained revenue requirement and rate data for California's utilities for the entire time that ERAM has been in effect. For Pacific Gas \& Electric (PG\&E), the data for 1982 to 1991 were contained in 13 CPUC decisions. Data for 1992 and 1993 were provided by the company. For Southern California Edison (SCE), the data for 1983 to 
1993 were contained in 15 CPUC decisions. ${ }^{25}$ For San Diego Gas \& Electric (SDG\&E), the data for 1982 to 1992 were contained in 13 CPUC decisions.

\subsection{California Electricity Rate History}

In the first stage of our review, we disaggregated the rate history of each utility into four categories of adjustments to overall revenue requirements: ECAC, ERAM, general rate case, and other. ECAC, California's fuel adjustment clause, consists primarily of fuel cost changes resulting from retroactive adjustments that "true-up" previous miscollections and prospective adjustments that are based on expected future fuel expenditures. ECAC also includes payments to QFs and recovery of utility DSM incentives. The ERAM balance should only contain income from sales-related mismatches between authorized revenues and actual revenues collected. In many cases, the ERAM balance included items not related to over or undercollections resulting from sales fluctuations. Usually, we were able to identify these other items and move them from the ERAM category to the "other" category. The general rate case (GRC) includes nonfuel revenue changes that are determined in those years when a complete rate case was held. The other category includes a wide range of revenue requirement changes. Attrition adjustments represent much of this category. However, there are many one-time adjustments that relate to particular construction projects or changes in tax laws included in this category.

Figure 6-1 shows changes in revenue requirements and retail rates from 1983 to 1993, for PG\&E, SCE, and SDG\&E, respectively. Note that the net effect of positive and negative revenue requirement adjustments does not equal the change in retail rates. The reason for this difference is that the sales forecast also changes in the annual adjustments.

The data clearly indicate that, in the overall context of California ratemaking, the clearing of ERAM balances has accounted for only a small proportion of the total change in revenue requirements in the last 10 years. Adjustments resulting from ECAC have been, by far, the dominant source of changes to revenue requirements. The compound effect of multiple, annual adjustments to revenue requirements is highlighted by the relatively small role played by the GRC in adjusting revenue requirements.

\footnotetext{
25 In 1987 SCE implemented a series of offsetting revenue requirement adjustments that had no impact on rates. These adjustments, which included $\$ 11.5$ million in increases and $\$ 11.5$ million in decreases, pertained to the phase-in of the Palo Verde nuclear plant, ERAM, and other rate base adjustments. We were unable to separate these offsetting changes into the appropriate rate categories.
} 
Figure 6-1. Changes in Authorized Revenue Requirement and Average Retail Rates
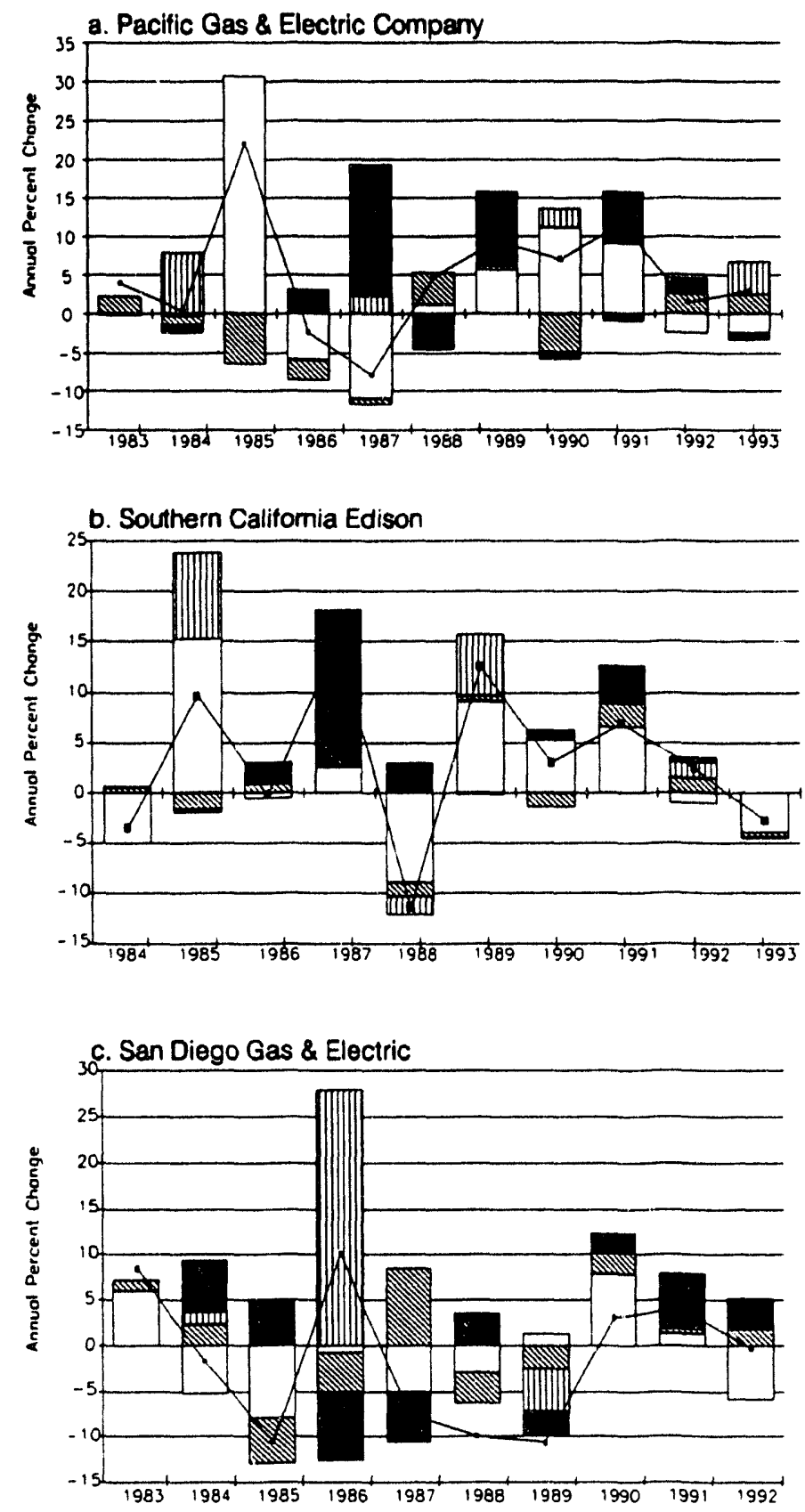

ECAC ERAM

Other $\rightarrow$ Avg. Retail Rates 


\subsection{Electricity Rate Changes With and Without ERAM}

The annual rate changes depicted in Figure 6-1 include ERAM adjustments to revenue requirements. In order to determine the effect of ERAM on rates, we also compared the actual rates, as reported above, to hypothetical rates, which exclude ERAM. To do this, we subtracted the ERAM balance from each year's revenue requirement and divided by authorized sales. ${ }^{26}$ Figure 6-2 shows annual changes in retail rate levels, both with and without the ERAM, for PG\&E, SCE, and SDG\&E, respectively. Table 6-1 summarizes these findings.

Table 6-1. Annual Percent Changes in Revenue Requirement and Retail Rates

\begin{tabular}{|c|c|c|c|c|c|c|c|c|c|}
\hline & \multicolumn{3}{|c|}{ PG\&E } & \multicolumn{3}{|c|}{ SCE } & \multicolumn{3}{|c|}{ SDG\&E } \\
\hline & $\begin{array}{l}\text { Rev. } \\
\text { Req. } \\
\text { (\%) }\end{array}$ & $\begin{array}{c}\text { Rates } \\
\text { W/ } \\
\text { ERAM } \\
(\%)\end{array}$ & $\begin{array}{c}\text { Rates } \\
\text { W/o } \\
\text { ERAM } \\
(\%)\end{array}$ & $\begin{array}{l}\text { Rev. } \\
\text { Req. } \\
(\%)\end{array}$ & $\begin{array}{l}\text { Rates } \\
\text { W/ } \\
\text { ERAM } \\
(\%)\end{array}$ & $\begin{array}{c}\text { Rates } \\
\text { W/o } \\
\text { ERAM } \\
(\%)\end{array}$ & $\begin{array}{l}\text { Rev. } \\
\text { Req. } \\
\text { (\%) }\end{array}$ & $\begin{array}{c}\text { Rates } \\
\text { W/ } \\
\text { ERAM } \\
(\%)\end{array}$ & $\begin{array}{l}\text { Rates } \\
\text { W/o } \\
\text { ERAM } \\
(\%)\end{array}$ \\
\hline 1983 & 2.0 & 4.0 & 1.7 & & & & 7.3 & 8.4 & 7.2 \\
\hline 1984 & 5.3 & 0.4 & 3.8 & -4.4 & -3.5 & -4.0 & 4.0 & -1.7 & -2.7 \\
\hline 1985 & 24.3 & 22.1 & 26.9 & 21.8 & 9.6 & 11.7 & -7.9 & -10.5 & -3.7 \\
\hline 1986 & .5 .6 & -2.4 & -4.3 & 2.5 & -0.2 & -2.3 & 15.2 & 10.1 & 8.3 \\
\hline 1987 & 7.6 & .7 .9 & -10.0 & 18.1 & 15.1 & 16.1 & -2.2 & .7 .3 & -18.3 \\
\hline 1988 & 0.7 & 4.8 & -0.2 & -9.2 & .11 .5 & -10.0 & -2.9 & -9.9 & 2.1 \\
\hline 1989 & 15.9 & 9.4 & 13.7 & 15.5 & 12.6 & 10.2 & -8.8 & -10.7 & -11.4 \\
\hline 1990 & 7.7 & 7.1 & 12.5 & 4.8 & 3.0 & 5.1 & 12.4 & 3.1 & -1.7 \\
\hline 1991 & 14.8 & 11.7 & 7.8 & 12.7 & 6.9 & 3.4 & 7.9 & 4.0 & 5.8 \\
\hline 1992 & 2.2 & 1.5 & -1.9 & 2.4 & 2.5 & 3.1 & -0.8 & -0.3 & .1 .7 \\
\hline 1993 & 3.5 & 3.0 & 3.0 & -4.6 & .2 .8 & -0.9 & & & \\
\hline Mean & 7.1 & 4.9 & 4.8 & 6.0 & 3.2 & 3.2 & 2.4 & -1.5 & .1 .6 \\
\hline Std. Dev. & 8.0 & 7.5 & 9.6 & 10.1 & 7.7 & 7.5 & 7.8 & 7.4 & 7.9 \\
\hline
\end{tabular}

The data indicate that, just as the magnitude of the ERAM adjustments has been a small factor influencing changes to authorized revenues, the rate impacts of ERAM have also

${ }^{26}$ This approach to measuring the effect of ERAM on rates assumes that, without ERAM, the monies accrued in the ERAM balancing account would not otherwise be recognized through some other revenue adjustment, such as attrition or more frequent rate cases. 
Figure 6-2. Changes in Average Retail Rates With and Without ERAM

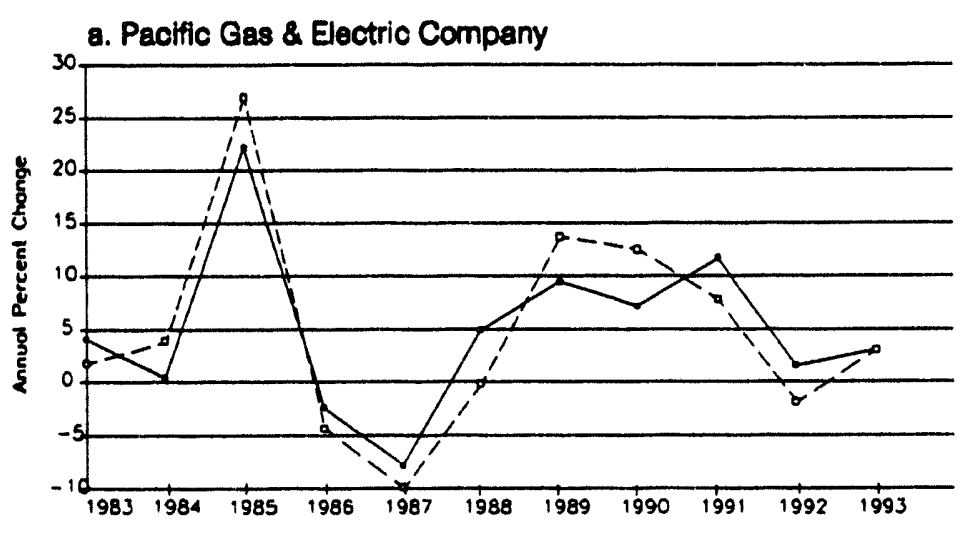

b. Southern Califomia Edison

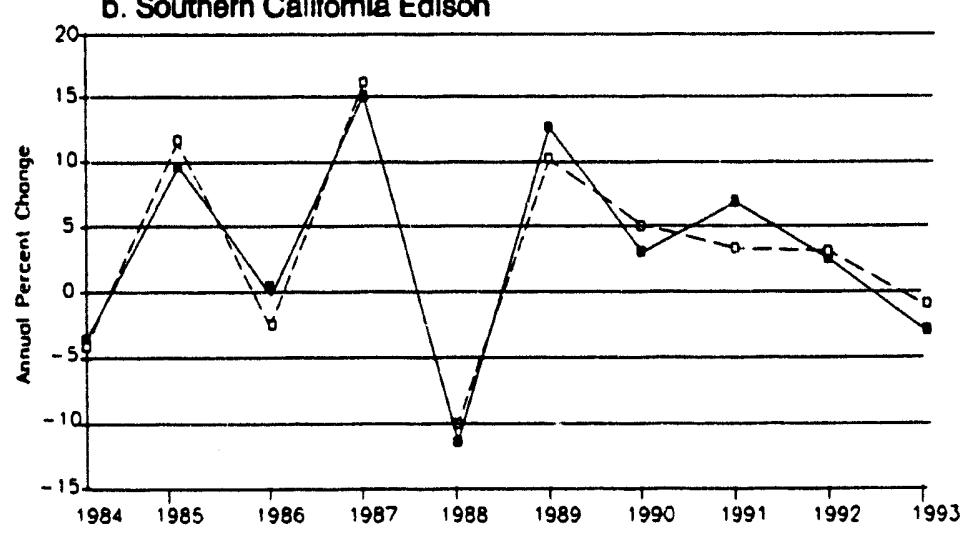

c. San Diego Gas \& Electric

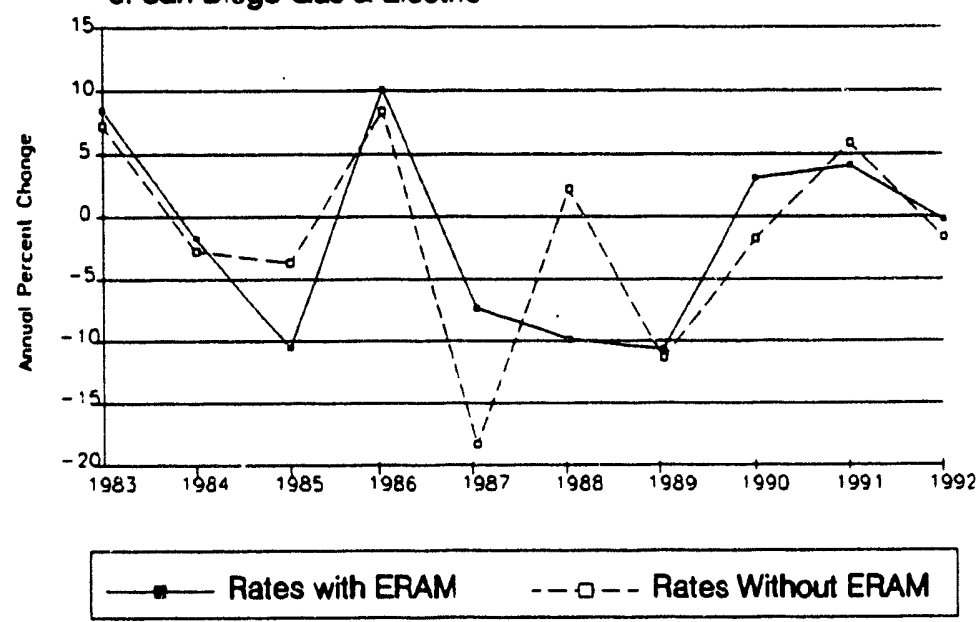


been small. For PG\&E, ERAM adjustments actually reduced rate volatility, as evidenced by a reduction in the standard deviation of annual rate changes from $9.6 \%$ to $7.5 \%$. For SCE and SDG\&E, ERAM has contributed little additional volatility to rates.

\subsection{Has ERAM Shifted Rate Risk?}

The typical argument for the existence of rate risk-shifting asserts that if demand is unexpectedly low and, through decoupling, the utility does not suffer from lost revenues because rates are raised, customers will bear the burden of higher rates. What this argument neglects is the correlation, or lack thereof, between rate fluctuation caused by decoupling and those fluctuations that are already present in the absence of decoupling. If this correlation happens to be greater than zero, then risks are being shifted; if this correlation is less than zero, then decoupling will actually reduce customer risk (i.e. increase customer utility assuming no bias). The magnitude of the correlation indicates the degree of transfer.

In the case of California's ERAM, we have estimated a decrease in the standard deviation of the utility's profit from about $4.4 \%$ to about $1.4 \%$ because of ERAM (see Chapter 5). Accompanying this, we have also estimated a decrease in the standard deviation of annual rate changes for two utilities (for PG\&E, 9.5\% to 7.5\%; for SDG\&E, 7.9\% to 7.4\%). Based on these estimates, we should conclude that for these two California utilities, there has been no risk shifting at all. Instead, ERAM has been accompanied by rate risk reductions to customers and profit risk reductions to utilities.

Of course, California's experience with ERAM cannot be generalized. In Appendix D, we continue this line of inquiry with a estimation of the cost of risk shifting using examples in which there has been some transfer of risk.

\subsection{Summary}

The history of decoupling in California suggests that: (1) decoupling has had a negligible effect on rate levels and has, for PG\&E, actually reduced rate volatility; (2) in terms of decoupling's relative impact, the rate changes resulting from the fuel adjustment clause have had far more dramatic effects on rates and, consequently, on the shifting of business risk from utility shareholders to utility ratepayers; and (3) when combined with our profitability analysis in Chapter 5, ERAM has, in fact, not been accompanied by any risk shifting at all for two of California's utilities. Thus, the larger issue for utility policy is that, in considering rate risk allocation and rate volatility issues, it is more appropriate 
to consider decoupling in the context of a comprehensive framework that jointly considers all sources of rate risk and rate volatility. ${ }^{27}$

${ }^{27}$ Appendix D discusses ERAM rate risk reallocation between shareholders and ratepayers. 


\section{Conclusions}

We believe there are three issues for utilities and regulators who are considering decoupling. First, the importance of lost revenues and therefore of decoupling depends strongly on pre-existing features of regulation. Notably, the frequency of rate cases and the design of fuel adjustment clauses directly influence the size and persistence of the disincentives that decoupling seeks to address. At the same time, we also believe there are other incentives (and disincentives) for utilities to build load, which are distinct from the lost revenue problem. Regulatory reforms, therefore, should not focus exclusively on lost revenues, but instead take a broad perspertive in trying to align utility incentives with the objectives of integrated resource planning.

Second, adoption of a decoupling mechanism requires consideration of the means by which revenues are set between rate cases, especially accounting for changes in nonfuel costs. Our examination of the empirical record suggests that, over short periods of time, neither load growth (which underlies traditional ratemaking) nor customer growth (which underlies RPC) provide a very powerful basis for explaining changes in these costs. In other words, the revenue-per-customer approach (in addition to decoupling sales from revenues) will on average do no worse than traditional ratemaking in tracking these costs. Thus, if cost-tracking is an important ratemaking objective, it is a separable concern from decoupling for which other approaches should be considered, such as attrition mechanisms or future test years.

Third, the record in California suggests that the issue of the additional rate volatility introduced by decoupling has been overemphasized. We believe that discussions of the additional rate volatility and risk-shifting associated with decoupling should be conducted in a framework that considers all sources of rate volatility and risk-shifting in ratemaking. In this framework, the questions of what the risks are and who is best suited to bear them can be made explicit and their treatment made comprehensive, rather than piecemeal.

Decoupling can play an important role in transforming utilities from sellers of a least-cost energy commodity to providers of least-cost energy services, but it is no panacea. While it can successfully eliminate an important disincentive for utility DSM programs, it must be designed carefully to take explicit account of other regulatory objectives, such as costtracking and rate volatility. 


\section{References}

American Gas Association (AGA) 1992. Introduction to Public Utility Accounting.

Binz, R. 1992. "Comments on Decoupling." Edison Times IRP Quarterly. October.

California Public Utilities Commission (CPUC) 1981. Decision 93887. Application 60153. December 30.

Chamberlin, J.H. 1992. "Weighing Decoupling Alternatives." Edison Times IRP Quarterly. October.

Council of Economic Advisors 1992. The Economic Report of the President - February 1991. Washington, DC: U.S. Government Printing Office. January.

DiValentino, L.M., T.L. Dittrich, J.E. Cuccaro, and A.M. Freedman 1992. "Revenue Decoupling Plus Incentives Mechanism." Regulatory Incentives for Demand-Side Management. Nadel, Reid and Wolcoti, ed. DC: ACEEE. ISBN 0-918249-16-3. pp. 125-139.

Eachus, R. 1993. Presentation to the NARUC Energy Conservation Committee. NARUC Summer Meeting. July 27.

Energy Information Administration (EIA) 1993. "Financial Statistics of Major Investor-Owned Electric Utilities 1991." DC: DOE/EIA. DOE/EIA-0437(91)/1. January.

Goldfard, L.K., and R.F. Spellman 1993. "DSM Incentives + ERAM = Bottom-Line Impact." Proceedings. 6th National Demand-Side Management Conference. Electric Power Research Institute (EPRI). p. 259. March.

Hirst, E. 1993. "Statistical Decoupling: A New Way to Break the Link Between Electric-Utility Sales \& Revenues." Oak Ridge, TN: Oak Ridge National Laboratory. ORNL/CON-372.

Hirst, E., and E. Blank 1993. "Regulating as if Customers Matter: Utility Incentives to Affect Load Growth." Boulder, CO: Land and Water Fund of the Rockies. January.

Jeynes, P.H. 1968. Profitability and Economic Choice. Ames: The Iowa State University Press

Krause, F., and J. Eto 1988. "Least-Cost Planning Handbook for Public Utility Commissioners: Volume 2 - The Demand Side: Conceptual and Methodological Issues." Washington, D.C.: National Association of Regulatory Commissioners (NARUC). LBL-25472. December.

Marnay, C., and G.A. Comnes 1990. "Ratemaking for Conservation: The California ERAM Experience." Berkeley, CA: Lawrence Berkeley Laboratory. LBL-28019. March.

Moskovitz, D. 1989. "Profits \& Progress Through Least-Cost Planning." Washington, DC: NARUC. November.

Moskovitz, D. 1992. "Why Regulatory Reform for DSM." Regulatory Incentives for Demand-Side Management. Nadel, Reid and Wolcott, ed. Washington, DC: ACEEE. pp. 1-19. 
Moskovitz, D. 1993. "Letters to the Editor: Reply to Richard Tempchin's letter 'Decoupling? Not So Fast'." The Electricity Journal. 6:2:2. March.

Moskovitz, D., C. Harrington, and T. Austin 1992. "Weighing Decoupling vs. Lost Revenues: Regulatory Considerations." The Electricity Journal. 5:9:58-63. November.

Moskovitz, D., C. Harrington, and T. Austin 1993. "Decoupling: Risks and Price Volatility." Draft. Gardiner, ME: The Regulatory Assistance Project. February 23.

Moskovitz, D., and G. Swofford 1991. "Decoupling Sales and Profits: An Incentive Approach That Works." The Electricity Journal. 4:6:46-53. July.

Nadel, S., M. Reid, and D. Wolcott 1992. Regulatory Incentives for Demand-Side Management. Washington, DC: ACEEE/NYSERDA.

Newbery, D.M.G., and J.E. Stiglitz 1981. The Theory of Commodity Price Stabilization, A Study in the Economics of Risk. Oxford: Clarendon Press.

Radford, B.W. 1992. "Rate-Making Trends in the 1980s: Readings and Rate Case Reports from PU Fortnightly 1978-1988." Arlington: Public Utilities Reports Inc.

Tempchin, R.S. 1993. "Letters to the Editor: Decoupling? Not So Fast." The Electriciry Journal. 6:2:2. March.

Train, K.E. 1991. Optimal Regulation, The Economic Theory of Natural Monopoly. Cambridge, MA: MIT Press. 


\section{Calculating the Profitability of Incremental Sales}

This Appendix supplements the discussions in Chapter 2 with the derivation of algebraic relationships among: (1) the magnitude of the variable cost elements affected by a sales increase as a fraction of total $(X)$; (2) the marginal rate at which the variable cost elements change with respect to the average rate of variable cost changes $(Y)$; (3) the initial profit margin $(Z)$; and (4) profits. We begin with the basic definition of profit:

$$
\pi=R-C
$$

$\mathrm{R}$ is revenue, $\mathrm{C}$ is costs, and the difference, $\pi$, is profit. Revenue is simply sales $(S)$ times price $\left(\mathrm{P}_{0}\right)$, which is assumed to remain fixed:

$$
R=S \times P_{0}
$$

Costs $(C)$ can be thought of as having both a fixed $(F C)$ and a variable $(V C)$ component:

$$
C=F C+V C
$$

Furthermore, in the base case, there is a fixed relationship between these costs, defined by $X$ :

$$
X=\frac{V C_{0}}{F C_{0}+V C_{0}}
$$

Now, introduce $Y$, which is the ratio of marginal variable costs to average variable costs, to account for the change in variable costs $(V C)$ with respect to a sales quantity, $S$, that is different from that in the base case $\left(S_{0}\right)$ :

$$
Y=\frac{\frac{V C-V C_{0}}{S-S_{0}}}{\frac{V C_{0}}{S_{0}}}
$$


The cost equation can now be written as:

$$
C=\left[\frac{V C_{0}}{X}-V C_{0}\right]+\left[V C_{0}+\frac{V C_{0}}{S_{0}} \times Y \times\left(S_{0}-S\right)\right]
$$

Of course, in the base case (where $S$ equals $S_{0}$ ), this equation reduces to:

$$
C_{0}=\frac{V C_{0}}{X}
$$

Now, let $Z$ equal the initial profit margin:

$$
Z=1-\frac{C_{0}}{R_{0}}
$$

which can be solved for $P_{0}$ :

$$
P_{0}=\frac{V C_{0}}{S_{0} \times X \times(1-Z)}
$$

The profitability equation can now be written as:

$$
\pi=\left[S \times \frac{V C_{0}}{S_{0} \times X \times(1-Z)}\right]-\left[\frac{V C_{0}}{X}+\frac{V C_{0}}{S_{0}} \times Y \times\left(S-S_{0}\right)\right]
$$

We are interested in the change in profit due to a change in sales:

$$
\frac{\pi-\pi_{0}}{\pi_{0}}=\frac{\left[S \times \frac{V C_{0}}{S_{0} \times X \times(1-Z)}-\frac{V C_{0}}{X}-\frac{V C_{0}}{S_{0}} \times Y \times\left(S-S_{0}\right)\right]-\left[S_{0} \times \frac{V C_{0}}{S_{0} \times X \times(1-Z)}-\frac{V C_{0}}{X}\right]}{\left[S_{0} \times \frac{V C_{0}}{S_{0} \times X \times(1-Z)}-\frac{V C_{0}}{X}\right]}
$$


Re-arranging terms yields:

$$
\frac{\pi-\pi_{0}}{\pi_{0}}=\frac{S-S_{0}}{S} \times \frac{1-Y \times X \times(1-Z)}{Z}
$$

This relationship was used to develop Figure 2-1.

We can also readily solve for the "break-even" condition in which there is no change in profit:

$$
1=X \times Y \times(1-Z)
$$

This relationship is summarized graphically in Figure A-1. Figure A-1 plots, for a range of variable costs expressed as a fraction of total costs, the size of the change required to eliminate all additional profits from the sales increase.

Considering the base situation presented in Chapter 2, in which $80 \%$ of total costs were assumed to be influenced by changes in sales, Figure A-1 indicates that the marginal change or responsiveness of these costs to the sales increase would have to be about 2.0 (in other words, a $1 \%$ increase in sales must correspond to a $2 \%$ increase in affected variable costs) in order to eliminate an increase in profits from the starting situation. As variable costs become a smaller fraction of total costs, the marginal change must be very large in order to offset an increase in profits. Figure A-1 indicates also that, for different initial profit margins, these conditions change only slightly as variable costs become a smaller fraction of total costs. 
Figure A-1. Break-Even Profitability for a $1 \%$ Increase in Sales

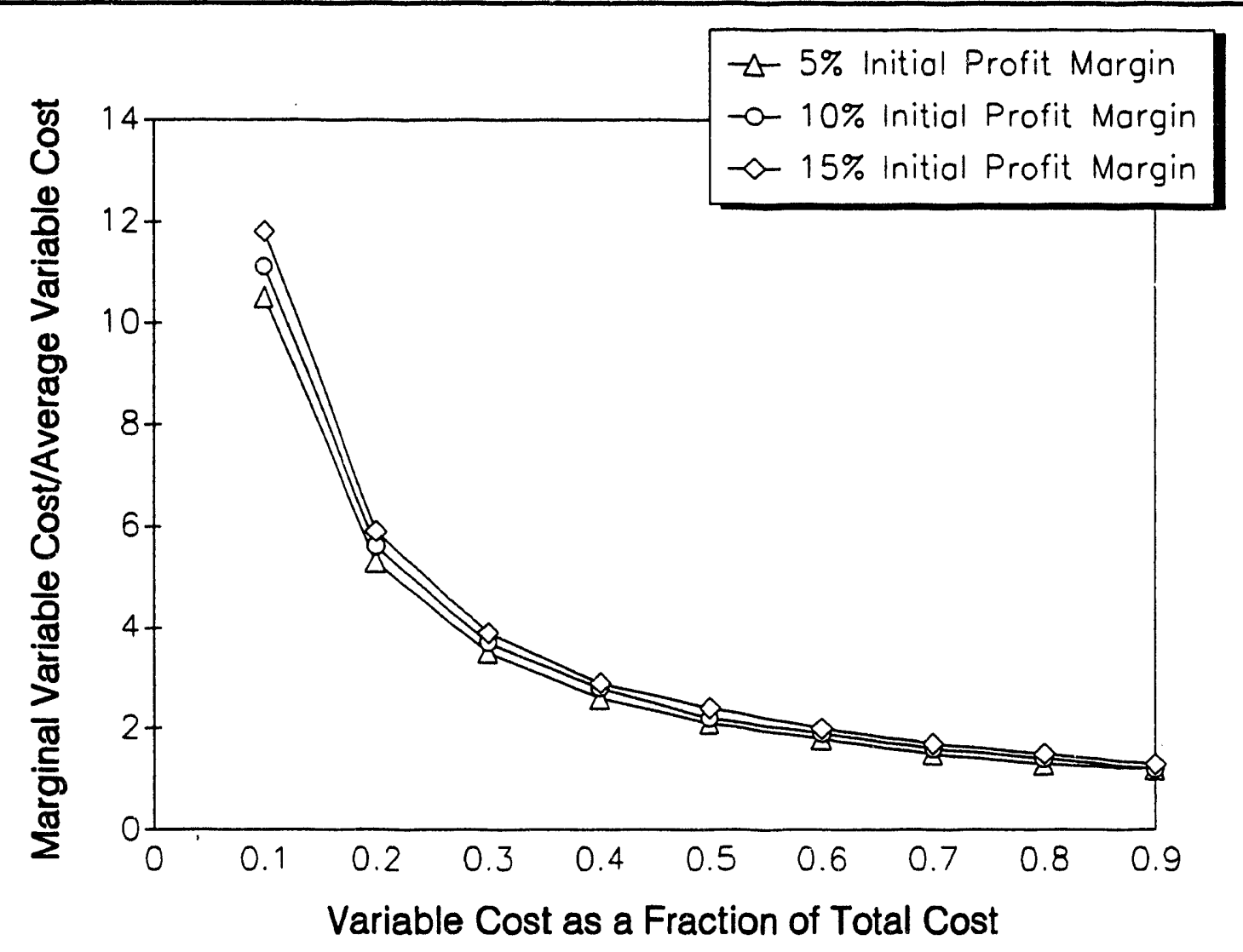




\section{Discussion of FERC Form-1 Data}

This appendix describes the data selection and screening process. We begin by defining the requirements that our data set had to meet in order to perform the regressions reported in Chapter 4 and Appendix C. Next, we describe the process used to screen the data, in order to limit the data set to only those utilities for which traditional retail ratemaking and deccupling were designed. Then, we list the individual utilities used in the analysis. Finally, we present summary operating statistics calculated using the FERC Form-1 data.

\section{B.1 Selecting a Data Source}

The two main criteria for selecting data for this project were that the data had to be national in scope and contain the variables necessary to evaluate the revenue adjustment mechanisms defined in Chapter 3. These variables include nonfuel cost, depreciation expense, return on rate base, equity capital, debt capital, sales, and customers.

We considered two sources of data: the U.S. Energy Information Administration (EIA) and the Edison Electric Institute (EEI). EIA conducts an annual survey of investorowned utilities and publishes the findings in Financial Statistics of Selected Electric Utilities and on computer tape. Federal law requires utilities to file this information, which is collected using FERC Form-1. EEI gathers similar data and publishes the Statistical Yearbook of the Electric Utility Industry. Reporting is voluntary, and the data are not readily available on computer tape. Accordingly, we chose to use the FERC Form-1 data.

The U.S. electric power industry is a combination of private, public, cooperative, and federal utilities. Private or investor-owned electric utilities account for more than threefourths of the revenues and sales in the industry, historically serving large consolidated markets. The Federal Energy Regulatory Commission (FERC) gathers information on "major" private electric utilities on Form-1. Major private electric utilities are defined as private utilities that have had during the past three consecutive calendar years, sales or transmission services that exceeded one of the following:

- 1 million megawatthours of total annual sales

- 100 megawatthours of annual sales for resale 
- 500 megawatthours of annual gross interchange out

- 500 megawatthours of wheeling for others

\section{B.2 Screening the Data}

We developed a four-step screening process to ensure data quality. First, we limited the data set to the types of utilities for which traditional retail ratemaking and decoupling were designed. That is, we eliminated utilities whose primary business is wheeling or wholesale power. Second, we identified and removed erroneous data. Third, we eliminated data that we could not use because accounting conventions resulted in negative nonfuel costs. Finally, we eliminated an observation if nonfuel costs changed by $30 \%$ or more in one year. These steps are now briefly summarized.

The regulations that we evaluate are designed for utilities that provide comprehensive electric services to ultimate customers. We screened the data to retain only those utilities whose primary operation and source of revenue is from sales to ultimate customers. In order for a utility to pass this screening process, it must have:

- at least 1,000 ultimate customers

- at least $100,000 \mathrm{kWh}$ of annual generation

- Power production expense

- Transmission expense

- Distribution expense

- Customer Service expense

This eliminated 89 utilities, representing 1,395 observations.

Next, we developed a system for identifying bad data. Missing values are one type of bad data. The FERC Form-1 tapes did not contain missing value indicators; however, by careful study of the data we were able to identify some zero entries as corresponding to missing values. Eleven observations were eliminated because of missing values. We also found instances where a utility had consistent values for a certain variable in every year except one or two. This eliminated 31 more observations.

We also eliminated data when accounting conventions made it impossible to calculate a meaningful nonfuel cost. Large credits in operation and maintenance expense accounts sometimes resulted in negative nonfuel production expenses. This is because the FERC standard set of accounts defines revenue from steam transfer, rent, and miscellaneous other power as a contra-expenses. This eliminated 97 observations. 
We decided to eliminate a utility in a given year if it reported a large change in nonfuel costs. There are two reasons for this. First, we wanted to eliminate the effect of utility mergers on our regression results. There were several mergers between 1964 and 1988 which resulted in dramatic, one-year increases in customers, sales, and nonfuel costs. Second, the goal of our regression analysis was to examine the relationship among customers, sales, and nonfuel expenses under normal operating conditions. Defining normal operating conditions is a subjective process. Ultimately, we eliminated observations where nonfuel costs changed by $30 \%$ or more in one year. However, it should be noted that the regression results were similar when we truncated at $10 \%, 30 \%$, or $50 \%$ changes in nonfuel costs. This eliminated 235 observations.

After completing the screening, our data set consisted of 3,278 observations representing 160 utilities. A list of company names and years of data used in our analysis is reported in Table B-1. 
Table B-1. Utilities and Reporting Years Used in LBL Analysis

Alabama Power

Company

(71,74,75,78-88)

Arizona Public Sorvice

Company

(65-71,74-84,87)

Citizens Utilities

(68, 70-88)

Arkansas Missouri

Power (65-80)

Arkansas Power 8 Light

(65-85.88)

Pacific Gas \& Electric

(65-88)

San Diego Gas \&

Electric (65-88)

Southem Califomi

Edison (65-82,84-88)

Public Service Company

of Colorado (65-88)

Connecticut Light \&

Power 167-81.83-88)

Hartiord Electric Light

(65-81)

United Illuminating

(65-88)

Delaware Power

Light (65-88)

Potomac Electric Power (65-88)

Florida Power (65-88)

Florida Power \& Light

(65-88)

Florida Public Utilitios

(65-86)

Gulf Power (65-88)

Tampa Electric (65-88)

Georgia Power $(65-88)$

Sovannah Electric \&

Power (65-88)

Hawailan Electric

(65-88)

Hilo Electric Light

(65-69,80-83)

Kauai Electric (65-68)

Maui Electric

(65-69,80-83,86)

Idaho Power

(65-77,80-88)

Central Illinois Electric

\& Gos $(65,66)$

Contral Iltinois Light

(65-88)

Contral lllinois Public

Service (65-88)

Commonwealth Edison

(65-88)

Illinois Power (65-88)

Mt. Carmel Public

Utility $(65-88)$
Indiana Michigan Electric (65-78,80-88)

Indianapolis Power 4

Light (65.88)

Northem Indiena Public

Service $(65-85,88)$

Public Service Company

of Indiana (65-85)

Southem Indiana Gas \&

Electric (65-88)

Interstate Power

(65-88)

lowa Eloctric Light \&

Power (65-88)

lowe llitinois Gas 8

Electric (65-88)

lowa Power \& Light

(65-88)

lowa Public Service

(65-88)

lowa Southem Utilities

(65-81, 84-88)

Central Kansas Power

(65.74)

Central Tolephone \&

Utilities (69-88)

Kansas Gas \& Electric

(65-88)

Kansas Power \& Light

(67-88)

Wostern Power \& Gas

$(66,67)$

Kentucky Power

(65-69, 73-88)

Kentucky Utilities

(65-88)

Louisville Gas \& Eloctric

(65-88)

Central Louisiana

Eloctric (65-88)

Gulf States Utilitios

(69-71, 74-86)

Louisiana Power \& Light

(65-85.88)

Now Orieans Public

Service (65-84)

Peoples Utilitios (66)

Bangor Hydro-Eloctric

(67-88)

Central Maine Power

(65-88)

Maine Public Service

(65.84, 87, 88)

Baltimore Gas \& Electric

(65-88)

Delmarva Power \&

Light (67.78)

Eastern Shoro Public

Service (65)

Potomac Edison

(65-74, 76-88)
Boston Edieon (65-88)

Commonweath Electric

(82-88)

Fitchburg 0 as \& Eloctric

Light (65-84,87,88)

Now Bodford Gas \&

Edison Light

$(65,67-70,72-80)$

Western Massachusetts

Eloctric (65-88)

Alpena Power (67-83)

Consumers Power

(65-84)

Dotroit Edison (65-88)

Edison Sautt Eloctric

(65-88)

Michigan Gas \& Electric (65-69,76-79,82-86)

Upper Peninsula Power

(65-88)

Minnesota Power \&

Light (65-88)

Northern States Power

(65-88)

Missisesippi Power

(65-88)

Mississippi Power \&

Light $(65-85,88)$

Empire District Electric

(65-88)

Kansas City Power \&

Light (65-88)

Missouri Public Service

(65-88)

St. Joseph Light \&

Power (65.88)

Union Electric (65-88)

Montana Power (65-88)

Nevada Power

(67-79,81-88)

Public Service of Now

Hampshire (65-84)

White Mountain Power

(65-68)

Atlantic City Electric

(67-88)

Jersey Central Power \&

Light $(67-71,73-79,88)$

New Jersey Power \&

Light (65-70)

Public Service Eloctric

8. Gas (65-88)

New Moxico Electric

Service

(65,70-72,75-81)

Public Service of New

Mexico (65-88)

Central Hudson Gas \&

Electric (65-88)

Consolidated Edison

(65-88)
Long Island Lighting

(65-84)

Now York State Eloctric

a Gas (65-88)

Niagara Mowhawk

Power (65-88)

Orange \& Rockland

Utilitios (65-88)

Carolina Power \& Light

(65-88)

Duke Power (65-88)

Nantahala Power \&

Light $(65-71,76-80)$

Montana-Dakota

Utilitios (65-88)

Otter Tail Power

(65-88)

Cincinnati Gas \&

Electric (65-88)

Cleveland Electric

liluminating (65-88)

Columbus \& Southern

Ohio Electric (65-88)

Dayton Power \& Light

(65-88)

Ohio Edison (65-88)

Ohio Power (65-88)

Tolodo Edison

(65-77,79-88)

Oklahoma Gas \&

Electric (65-88)

Public Service of

Oklahoma (65-88)

Califomia-Pacific

Utilitios (65-84)

Pacific Power \& Light

(65-88)

Portland General

Electric (65-88)

Duquesne Light (65-88)

Motropolitan Edison

(65-79)

Pennsylvania Eloctric

(65-83, 86-88)

Pennsylvania Power

(65-88)

Ponnsylvania Power \&

Light (65-88)

Philadelphia Electric

(65-88)

United Gas

Improvement (65-88)

West Penn Power

(65-88)

Narragansett Electric

(65-88)

Newport Electric

(65-77,80-83,86-88)

South Carolina Electric

\& Gas (65-83,85-88)

Black Hills Power \&

Lioht (65-88)

Northwestem Public

Service (65-88)

Contral Power \& Light

(65-87)

Community Public

Service (65-80)

Dallas Power \& Light

(65-82)

El Paso Electric (65-88)

Gulf States Utilitios

(65-67)

Houston Lighting \&

Power (65-88)

Southweetem Electric

Power (65-88)

Southwestern Public

Service (65-88)

Toxas Electric Sorvice

(65.82)

Toxas Power \& Light

(65-82)

Toxas Electric Utilitios

(84-88)

Wost Toxas Utilitios

(65-88)

Utah Power \& Light

(65-88)

Contral Vormont Public

Service (65-88)

Citizens Utilities $(65,66)$

Groen Mountain Power

(65-88)

Potomac Edison of

Viroinia (66-73)

Virginia Electric \&

Power (65-88)

Puget Sound Pówer \&

Light (65-88)

Washington Water

Power (65-88)

Appalachian Power

(65-71.74-88)

Monongahela Power

(65-88)

Potomac Edison of 


\section{Discussion of Statistical Analysis}

This appendix describes additional statistical analyses performed using FERC Form-1 data. We begin by summarizing the regressions models described in Chapter 4, which included cost, sales, and customer variables. These models provided the basis for our evaluation of different revenue adjustment mechanisms in Chapter 5 . We then introduce three extensions to the Chapter 4 models. First, we added variables to our original model to the see if we could improve its explanatory power. Second, we examined changes in capital and customers over several years to determine whether a time lag exists between an increase in the independent variables, capital and customers, and an increase in nonfuel costs. Third, we tried to distinguish between expected and unexpected changes in sales growth.

\section{C.1 Cost, Sales, and Customers}

We begin this discussion by presenting the non-fuel cost, sales, and customer regression models from Chapter 4. These models examine the relationship between changes in , nonfuel costs and changes in sales and customers. First, we regressed changes in nonfuel costs on changes in sales and customers separately:

$$
\begin{array}{ll}
\% \Delta C=\underset{(.016)}{0.399} \cdot \% \Delta S & R^{2}=0.15 \\
\% \Delta C=0.72 \cdot \% \Delta N & R^{2}=0.14
\end{array}
$$

Then, we constructed a model that would capture the effect of changes in sales and customers simultaneously. In this model, we specify a sales-related term in the form of sales-per-customer. Simply including sales would be inappropriate because some sales growth is already accounted for by the number of customers. Sales-per-customer allows us to estimate the residual sales-driven costs separately from those that are driven by the number of customers. In addition, we added an intercept term, which captures changes in costs that are not related to sales or the number of customers. 


$$
\begin{aligned}
& \% \Delta C=0.029+0.035 \cdot \% \Delta L P C+0.305 \cdot \% \Delta N \quad R^{2}=0.02 \\
& \begin{array}{lll}
(0.002) & (0.023) \quad(0.035)
\end{array}
\end{aligned}
$$

\section{C.2 Additional Variables}

Clearly, neither changes in sales nor customers explains a significant amount of the changes in non-fuel cost, as evidenced by the low $\mathrm{R}^{2}$ terms. We tried other formulations of the basic sales and customer models to identify other variables that may have a significant effect on changes in cost. Many attrition proceedings adjust rates based on changes in capital levels and interest rates. We added these variables to our model, using company-specific capital levels and the average annual interest rate of AAA bonds. We also included a variable for annual changes in U.S. gross domestic product.

\begin{tabular}{|c|c|c|c|c|c|c|c|}
\hline & Intorcopt & $\begin{array}{c}\% \Delta \\
\text { Salos Per } \\
\text { Customer }\end{array}$ & $\begin{array}{c}\% \\
\Delta \\
\text { Customers } \\
\end{array}$ & $\begin{array}{c}\% \Delta \\
\text { Capital } \\
\end{array}$ & $\begin{array}{l}\% \Delta \\
\text { GDP }\end{array}$ & $\begin{array}{r}\% \Delta \\
\text { Int. Rates } \\
\end{array}$ & $R^{2}$ \\
\hline Step 1 & $\begin{array}{c}.03 \\
(29.4)\end{array}$ & & & $\begin{array}{c}.13 \\
(11.6)\end{array}$ & & & .04 \\
\hline Step 2 & $\begin{array}{c}.03 \\
(20.8)\end{array}$ & & $\begin{array}{c}.28 \\
(8.2)\end{array}$ & $\begin{array}{c}.13 \\
(11.4)\end{array}$ & & & .06 \\
\hline Step 3 & $\begin{array}{c}.03 \\
(21.0)\end{array}$ & & $\begin{array}{c}.29 \\
(8.5)\end{array}$ & $\begin{array}{c}.13 \\
(11.3)\end{array}$ & & $\begin{array}{l}-.04 \\
(-3.8)\end{array}$ & .06 \\
\hline Step 4 & $\begin{array}{c}.04 \\
(16.9)\end{array}$ & & $\begin{array}{l}.29 \\
(8.6)\end{array}$ & $\begin{array}{c}.13 \\
(11.4)\end{array}$ & $\begin{array}{l}-.19 \\
(-3.8)\end{array}$ & $\begin{array}{l}-.05 \\
(-4.7)\end{array}$ & .07 \\
\hline Step 5 & $\begin{array}{c}.04 \\
(16.7)\end{array}$ & $\begin{array}{c}.05 \\
(2.2)\end{array}$ & $\begin{array}{c}.31 \\
(8.8)\end{array}$ & $\begin{array}{c}.13 \\
(11.0)\end{array}$ & $\begin{array}{c}-.24 \\
(-4.4)\end{array}$ & $\begin{array}{l}-.06 \\
(-5.0)\end{array}$ & .07 \\
\hline
\end{tabular}

Table C-1. "Stepwise" Regression Results

To understand the effect of each variable on the $\mathbf{R}^{2}$ term, we added one variable at a time to the model using the Statistical Analysis System's "stepwise" procedure. This procedure begins with no variables in the model. For each of the independent variables, "stepwise" calculates an F statistic that reflects the variable's contribution to the explanatory power of the model if it is included. "stepwise" adds the variable with the largest $\mathrm{F}$ statistic to the model, and the process is repeated. After a variable is added, "stepwise" looks at all the variables already included in the model and deletes those that 
do not produce an F statistic above a specified level. In our analysis, no variables were deleted after being added to the model. The results of the individual steps are contained in Table C-1.

\section{C.3 Lagged Variables}

Table C-2. Lagged Variable Regression Results

\begin{tabular}{|c|c|c|}
\hline \multirow{2}{*}{ Independent Variable } & \multicolumn{2}{|c|}{ Annual \% Change in Non-Fuel Cost $\mathrm{B}^{2}=.17$} \\
\hline & Estimate & T - Statistic \\
\hline Intercept & 0.03 & 11.9 \\
\hline$\% \Delta$ Capital (t-1 to $t)$ & 0.11 & 7.8 \\
\hline$\% \Delta$ Capital (t-2 to $t-1)$ & 0.09 & 5.9 \\
\hline$\% \Delta$ Capital (t-3 to $t-2)$ & 0.12 & 8.5 \\
\hline$\% \Delta$ Capital $(t-4$ to $t-3)$ & 0.08 & 5.7 \\
\hline$\% \Delta$ Capital (t-5 to $t-4)$ & 0.00 & 1.1 \\
\hline$\% \Delta$ Customers (t-1 to $t)$ & $\cap 22$ & 6.0 \\
\hline$\% \Delta$ Customers (t-2 to $t-1)$ & & -0.6 \\
\hline$\% \Delta$ Customers (t-3 to $t-2$ ) & & 2.1 \\
\hline$\% \Delta$ Customers (t-4 to $t-3)$ & -0.01 & -0.21 \\
\hline$\% \Delta$ Sales per Cust (t-1 to $t$ ) & 0.02 & 0.9 \\
\hline$\% \Delta \operatorname{GDP}(t-1$ to $t)$ & -0.16 & -2.6 \\
\hline$\% \Delta$ Interest Rates ( $t-1$ to $t$ ) & -0.06 & -4.8 \\
\hline
\end{tabular}

Results from the "stepwise" regressions indicate that percent change in capital and customers are the best predictors of changes in nonfuel cost. Next, we expanded the "Step 5" equation listed in Table C-1 to include several years of changes in capital and customers. We stopped adding years to our modei when the estimate for a variable was no longer significant at the $5 \%$ level. This resulted in a model with five years of annual changes for capital and four years of annual changes for customers. This increased our $\mathrm{R}^{2}$ term from .07 to .17. See Table C-2. 
By adding together the individual estimates for capital and customers we calculate a five year cumulative estimate of 0.39 for $\Delta \%$ capital and a four year cumulative estimate of 0.26 for $\Delta \%$ customers.

\section{C.4 Expected and Unexpected Changes}

Table C-3. Expected and Unexpected Sales Change Regressions

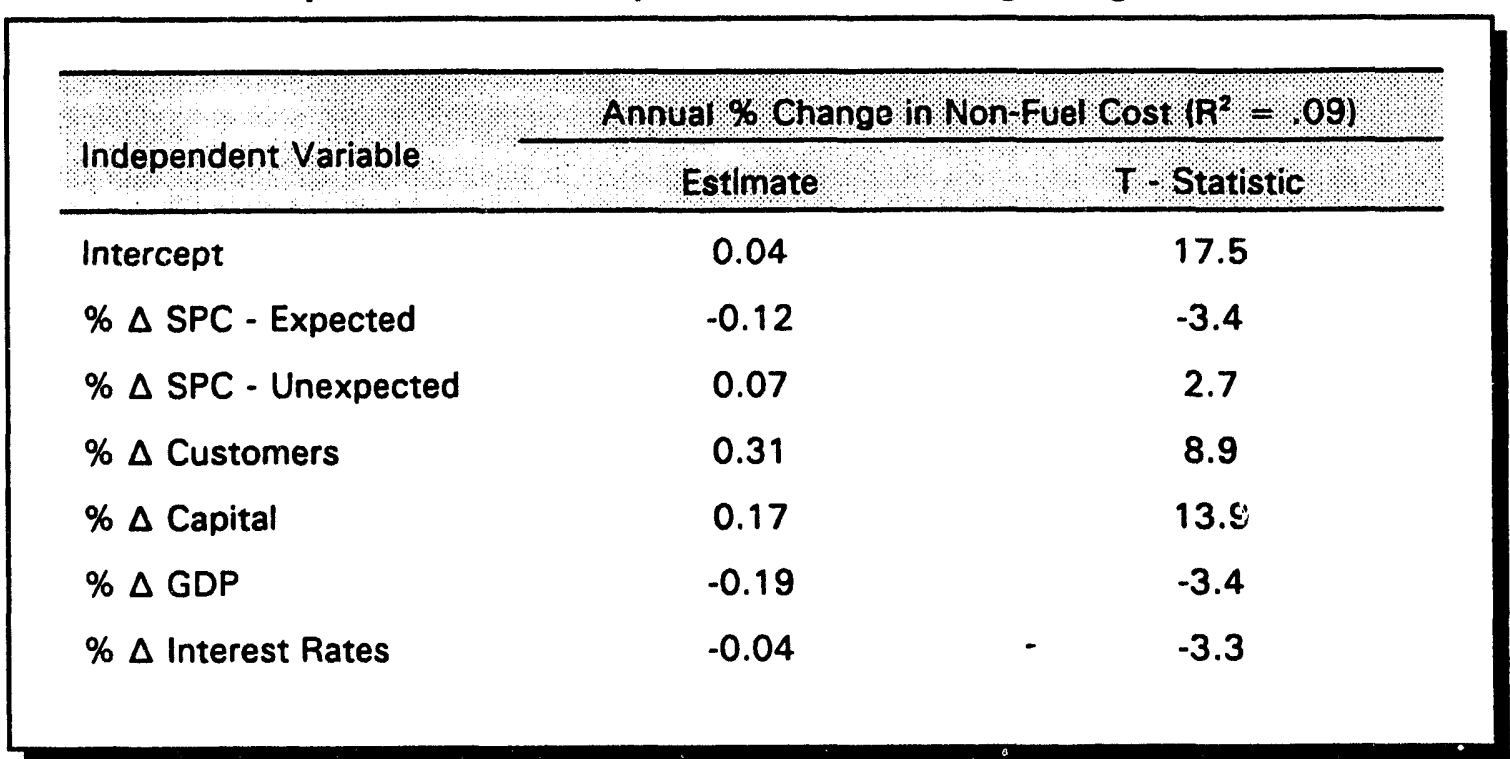

We also tried to determine whether the changes were due to differences between expected and unexpected changes in sales per customer (SPC). We define expected change in SPC for each company as the average change in SPC for that company over the previous two years. Unexpected change in SPC is simply actual change in SPC less expected change in SPC. For example, if Company X's average SPC change during the last two years was $3 \%$ and actual SPC change in the current year is $4 \%$, then expected percent change in SPC equals 3\% and unexpected percent change in SPC equals $1 \%$. See Table C-3. This regression indicates that expected sales growth decreases nonfuel costs while unexpected sales growth increases nonfuel costs. It seem. implausible that "expected" sales growth would actually reduce nonfuel costs. 


\section{C.5 Summary}

In Chapter 4 we showed that one-year changes in the number of customers have a fairly strong one-year impact on nonfuel costs but that one-year changes in sales have a rather weak effect. However, Chapter 4's results show that, even after accounting for the effects of these two variables and the autonomous trend or constant term, the vast majority of the year-to-year variation in nonfuel costs remains unexplained. In this appendix, we tried to identify factors, other than sales and customers, that contribute to changes in nonfuel costs.

First, we added additional variables to our regression model, including company-specific capital levels, national economic growth (GDP), and prevailing interest rates. The results of our analysis using the Statistical Analysis System's "stepwise" procedure indicate that changes in capital levels have the largest effect on changes in nonfuel costs, followed by changes in customers, interest rates, economic growth, and sales per customer, respectively. Using these five independent variables and a constant term the $\mathrm{R}^{2}$ increased to .07 , as compared to an $\mathrm{R}^{2}$ of .02 reported in Chapter 4 . However, even with these additional explanatory variables, the vast majority of the year-to-year variation in nonfuel costs remains unexplained.

Second, we expanded our regression model to include the effect of more than one year of changes in capital and customers. Using five years of changes in capital levels and four years of changes in customers, the $\mathrm{R}^{2}$ term increased from .07 to .17 .

Finally, we more closely scrutinized the relationship between sales per customer and nonfuel costs. Specifically, we separated the effects of expected and unexpected changes in sales per customer. This regression indicates that expected changes in sales per customer reduces nonfuel costs while unexpected changes increase nonfuel costs. We find it highly unlikely that nonfuel costs actually decrease when expected sales growth increases.

The regression work described in this appendix was based on industry data spanning from 1964 to 1988 . The electric utility industry has undergone major structural changes during this time period. Before 1972 the industry experienced declining real costs and steady sales growth. In contrast, in the 1980's the industry embarked on large construction programs that increased real costs while sales growth became increasingly uncertain. Accordingly, the results of our statistical analysis should be carefully applied to the utility industry as it exists today. 
$\longrightarrow$ 


\section{Calculating the Cost of Risk}

A successful decoupling mechanism can reduce a utility's risk of demand fluctuations, which is one of decoupling's primary purposes. But reductions in a utility's risk are not free; generally it is asserted that they come at the cost of increased risk to customers. Based on the experience of California utilities with ERAM, we expressed the concern that this assertion may be wrong (see Chapter 6).

California's experience with ERAM cannot, however, be used to make general statements about the risk-shifting implications of decoupling. In this appendix, we describe a method for making a quantitative estimate of the burden of any risk that is shifted and will make a rough calculation of its magnitude for an arbitrary but small increase in customer risk. Because our two best estimates of changes in consumer risk are PG\&E at $-2 \%$, and SDG\&E at $-0.5 \%$, it appears that any risk shift would be quite small, probably on the order of $1 \%$. So our hypothetical example will be for an increase in consumer risk of $1 \%$.

\section{D.1 Is Rate Risk Correlated with Consumer Income?}

A central question in the analysis of any risk is always the correlation of that risk with the bearer's portfolio. If the risk is correlated, then it adds much more to the bearer's risk than if it is uncorrelated. For instance if a customer's income uncertainty is $\$ 1000$ and we add to that an uncorrelated risk of $\$ 100$, then his total uncertainty is only $\$ 1005^{28}$, while if we add a correlated risk of $\$ 100$, his uncertainty will climb to $\$ 1100$. This is simply the result of the laws of variance and covariance for random variables. These are:

$$
\begin{aligned}
& \operatorname{Var}(X+Y)=\operatorname{Var}(X)+\operatorname{Var}(Y)+2 \operatorname{Cor}(X, Y) S D(X) S D(Y) \\
& S D(X+Y)=S Q R T(\operatorname{Var}(X+Y))
\end{aligned}
$$

One would expect a customer's income to be correlated with the utility's revenue collection (without a decoupling revenue adjustment mechanism or RAM) because both are subject to macroeconomic influences. In other words, when the economy is good, revenues will be up, and a customer is likely to be doing better financially. Of course

\footnotetext{
${ }^{28}$ For uncorrelated variables, the variances are additive. Thus the total variance is $1,000,000+10,000$. The standard deviation is the square root of the variance or approximately 1,005 .
} 
the correlation is far from perfect: some customers lose their jobs or have unanticipated expenses in good times, and some get raises in bad times. We will assume a rather high correlation of 0.5 in order to put an upper bound on the impact of risk from RAMs. Thus, we assume that rate increases dictated by the RAM balancing account often occur in conjunction with customer's negative income fluctuations.

Next we turn to the magnitude of the fluctuations. The typical household electric bill is about $\$ 1,000 /$ year, and, as explained above, we will analyze an increase in the standard deviation of rates of $1 \%$. This produces a uncertainty of about $\$ 10$ in the customer's electric bill. We need three more inputs for our calculations: (1) income, (2) standard deviation of income, and (3) risk aversion. In order to present a conservative estimate of the value of risk, we will assume an low income $(\$ 30,000 /$ year), a high standard deviation (\$6,000/year), and a high risk aversion (2.0). This figure for risk aversion is for constant relative income risk aversion as defined and documented by Newbery and Stiglitz (1981). It essentially measures the curvature of an individual's utility function and is a dimensionless number.

As a preliminary calculation, we find that with a correlation of 0.5 , the $\$ 10$ uncertainty increases the income uncertainty of the customer from $\$ 6,000$ to $\$ 6,015$. We can now apply the risk-premium formula from Newbery and Stiglitz, which uses risk aversion, $R$, the coefficient of variation in income, $\sigma$, and the expected income $Y$.

We compute the pre-RAM consumer risk premium as:

$$
\begin{gathered}
\rho=\frac{1}{2} R \cdot \sigma^{2} \cdot \bar{Y} \\
\rho=\frac{1}{2} \cdot 2 \cdot(6,000 / 30,000)^{2} \cdot \$ 30,000=\$ 1,200
\end{gathered}
$$

For the post-RAM consumer, the risk premium is:

$$
\rho=\frac{1}{2} \cdot 2 \cdot(6,005 / 30,000)^{2} \cdot \$ 30,000=\$ 1,202
$$

So we see that the increase in risk premium resulting from the RAM is about $\$ 2$, or $0.2 \%$ of electricity revenue. As we have indicated, this is probably an overestimate. If, for example, the correlation between individual customer income and the utility's revenue fluctuations is much less than half, which may well be the case, this could be a substantial overestimate.

To give the reader an idea of the sensitivity of our results to such changes in these assumptions, we have recomputed the risk premium for several sets of assumptions. The 
results are presented in Table D-1. The interested reader can easily guess how slightly changes in any of these assumptions would affect the results simply by noting whether the variable affects the outcome linearly or quadratically.

\section{Table D-1. Calculation of Risk-Shifting Premiums}

\begin{tabular}{|c|c|c|c|c|c|}
\hline $\begin{array}{l}\text { Risk } \\
\text { Aversion }\end{array}$ & $\begin{array}{l}\text { Electric Bill } \\
\text { Uncertainty } \\
\text { (\$/year) }\end{array}$ & $\begin{array}{l}\text { Standard } \\
\text { Deviation } \\
\text { of Income } \\
\text { (s/yearl }\end{array}$ & $\begin{array}{l}\text { Income } \\
\text { (s/year) }\end{array}$ & Correlation & $\begin{array}{l}\text { Electric Bill } \\
\text { Risk } \\
\text { Premium } \\
\text { ( } \$ \text { /year) }\end{array}$ \\
\hline $\begin{array}{l}2.0 \\
1.0 \\
2.0 \\
2.0 \\
2.0 \\
2.0\end{array}$ & $\begin{array}{l}30 \\
30 \\
15 \\
30 \\
30 \\
30\end{array}$ & $\begin{array}{l}6,000 \\
6,000 \\
6,000 \\
3,000 \\
3,000 \\
6,000\end{array}$ & $\begin{array}{l}30,000 \\
30,000 \\
30,000 \\
30,000 \\
15,000 \\
30,000\end{array}$ & $\begin{array}{l}0.5 \\
0.5 \\
0.5 \\
0.5 \\
0.5 \\
0.25\end{array}$ & $\begin{array}{l}\$ 2.00 \\
\$ 1.00 \\
\$ 1.00 \\
\$ 1.00 \\
\$ 2.00 \\
\$ 1.00\end{array}$ \\
\hline
\end{tabular}

The cost of risk to the customer also needs to be considered in the context of the broader picture. The utility has had its revenue fluctuations reduced by $3 \%$, and because profit is only about $12 \%$ of revenue, this should reduce fluctuations in profit by about $24 \%$. This in turn should lead to a reduction in the cost of capital, which, if returned to ratepayers, would lead to lower rates. It is possible that passing these reductions on may save customers more than the cost of the extra risk. ${ }^{29}$

${ }^{29}$ On the other hand, the empirical record is currently very weak on the impact ERAM has had on the cost of capital for California utilities compared to other utilities. 

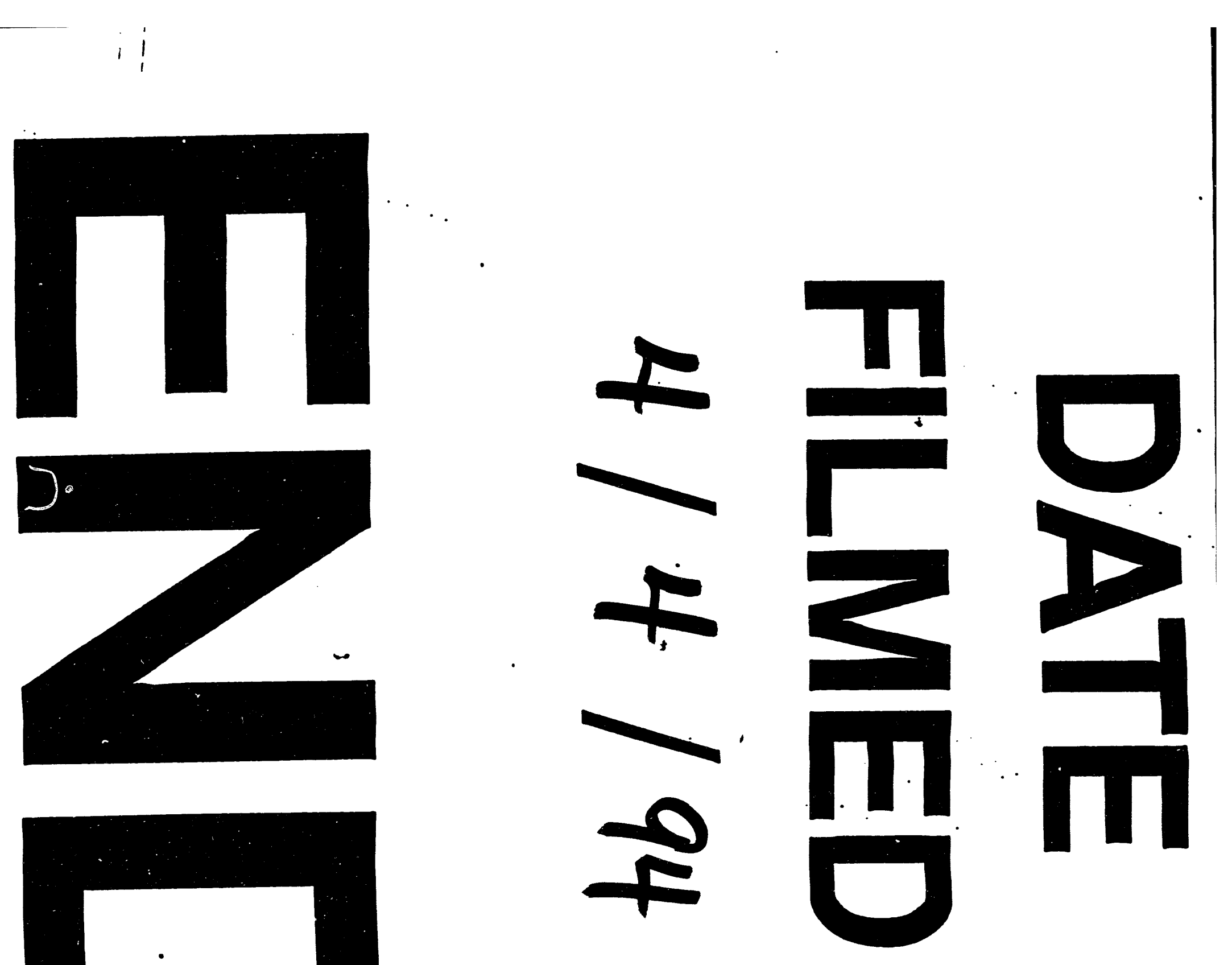
$\overline{-}$

. 